\title{
Transcriptome analysis of ruminal epithelia revealed potential regulatory mechanisms involved in host adaptation to gradual high fermentable dietary transition in beef cattle
}

\author{
K. Zhao ${ }^{1,2}$, Y. H. Chen ${ }^{1}$, G. B. Penner ${ }^{3}$, M. Oba ${ }^{1}$ and L. L. Guan ${ }^{1 *}$
}

\begin{abstract}
Background: The transition from a high forage to a highly fermentable diet can induce digestive disorders in the rumen. To date, the host mechanisms that regulate the adaption to such dietary transition are largely unknown. To understand the molecular mechanisms involved in such phenomena, RNA-sequencing was performed to identify the changes in the transcriptome of ruminal epithelia during gradual transition from a diet containing 0\% to 89\% grain.

Results: In total, the expression of 11,044, 11,322 and 11,282 genes were detected in ruminal epithelia of beef heifers ( $n=15)$ fed $0 \%, 72 \%$ and $89 \%$ barley grain diet, respectively. The transcriptome profiles of rumen epithelia differed between low grain diet (LGD) (0\% grain) and high grain diet (HGD) (72\% and 89\%), and HGD tended to reduce the expression of genes involved in epithelial catalytic and binding activities. When diet was changed from $72 \%$ to $89 \%$ grain, the mean ruminal pH change was significantly different among individual heifers with five of them decreased (down group (DG); from 6.30 \pm 0.09 to $5.87 \pm 0.15, P<0.01$ ) and five of them increased (up group (UG); from $5.84 \pm 0.42$ to $6.35 \pm 0.37, P<0.05)$. The functional analysis of differentially expressed $(D E)$ genes revealed inhibited "Immune response of leukocytes", "Attraction of phagocytes", and "Cell movement of leukocytes" ( $P<0.05)$ functions (Z-score $=-2.2,-2.2$ and -2.0, respectively) in DG, and inhibited "Concentration of lipid" and "Proliferation of epithelial cells" functions in UG (Z-score $=-2.0$, and -1.8 , respectively). In addition, the expression of genes involved in ketogenesis (HMGCL) and lipid synthesis (SREBF2, FABP4) was increased in DG, while the expression of ketogenesis (ACAT2, HMGCS) and cholesterol synthesis related genes (HMGC and FDPS) were deceased in UG. Furthermore, the upstream regulators were found to be involved in the regulation of immune response and cell cycle progress, and SNP (g.46834311A > G) in FABP4 was identified between two groups of animals $(P<0.1)$.
\end{abstract}

Conclusion: The identified genes, upstream regulators, and SNP could be potential genetic markers that may account for the varied individual ruminal $\mathrm{pH}$ responses to the dietary transition stress.

Keywords: Transcriptome, Ruminal epithelia, Adaptation, Dietary transition, Beef cattle

\section{Background}

To meet the global demand for meat consumption, it has become a common practice in the beef industry to use intensive feeding strategies such as high energy and high concentrate diets to finish cattle [1]. However, feeding high concentrate diets has been reported to be

\footnotetext{
* Correspondence: Iguan@ualberta.ca

${ }^{1}$ Department of Agricultural, Food and Nutritional Sciences, University of

Alberta, 416 F Agr/For, Edmonton, AB T6G2P5, Canada

Full list of author information is available at the end of the article
}

associated with digestive disorders that could lead to ruminal acidosis [2], laminitis [3], liver abscesses [4], and hindgut acidosis [5] in cattle.

When cattle are fed high fermentable diets, the increase and accumulation in short chain fatty acid (SCFA) production together with subsequent decrease in ruminal $\mathrm{pH}$ are usually observed due to increased microbial fermentation [6]. In the meantime, ruminal epithelium plays an important role in response to the ruminal $\mathrm{pH}$ change and regulation via SCFA absorption [7-9]. 
Therefore, highly fermentable diets could partly elicit an adaptive response by rumen epithelium to maintain the normal function of rumen. Indeed, when a gradual transition strategy is applied, ruminants have strong ability to adapt to highly fermentable diet $[2,10]$. However, the individual variation in the adaptation to high concentrate diet has been widely observed in both beef cattle $[2,11]$ and dairy cows $[12,13]$. It is suggested that the differences in the rate and ways of SCFA absorption by the animal may explain the individual variation in the severity of subacute ruminal acidosis in sheep [8]. Recently, Schlau et al. [11] reported that the expression of sodium hydrogen exchanger isoform 3 (NHE3) gene was different between acidosis-resistant and acidosissusceptible steers during rapid high grain diet transition, indicating the differences in intracellular proton removal could be attributed to variation in the host response.

To date, the underlying regulatory mechanisms for the host response to ruminal $\mathrm{pH}$ change has not been well defined. In this study, we aimed to identify the molecular mechanisms for variation in the response to a gradual transition to a high grain diet within the same animal by characterizing the global gene expression pattern of ruminal epithelia using RNA-seq based transcriptome profiling. The identified mechanisms may help to explain the observed animal variation in maintaining a balanced ruminal $\mathrm{pH}$, which provide new insight into decreasing risk of ruminal acidosis for the beef industry.

\section{Results}

Rumen epithelial transcriptomes fed $0 \%, 72 \%$ and $89 \%$ grain diets

A total of 1130 million $(25.11 \pm 2.89$ million reads per sample) high-quality 100-bp paired-end reads were obtained from 45 ruminal papillae samples collected from 15 heifers fed diets containing $0 \%, 72 \%$, and $89 \%$ grain, respectively. Of these reads, $\sim 86.1 \%$ of them were mapped to the bovine genome (UMD 3.1) and the expression of 11,044, 11,322 and 11,282 genes were detected (with reads per million (RPM) > 1 in 15 heifers fed each diet) in the ruminal epithelial tissue under each dietary condition, respectively. Among them, the expression of 10,880 genes was commonly detected from three dietary conditions (Fig. 1a). The most relevant gene ontology (GO) terms of these commonly expressed genes were "catalytic activity" and "bindings", followed by "nucleic acid binding transcription factor activity", "structural molecular activity", "enzyme regulator activity", and "receptor activity" (Fig. 1b). When the transcriptome profiles were further compared among three diets, the dietary-dependent expression of genes was detected, with 43, 119 and 102 genes expressed only in $0 \%, 72 \%$ and $89 \%$ grain, respectively (Fig. 1a). Further analysis on these diet-dependent genes using DAVID (Database for Annotation, Visualization and Integrated Discovery) showed different functional annotation clusters (Additional file 1 worksheet 2). For example, the enriched gene ontologies for 43 genes under $0 \%$ grain diet were "immune response" and "inflammatory response", and for the 119 genes under $72 \%$ grain
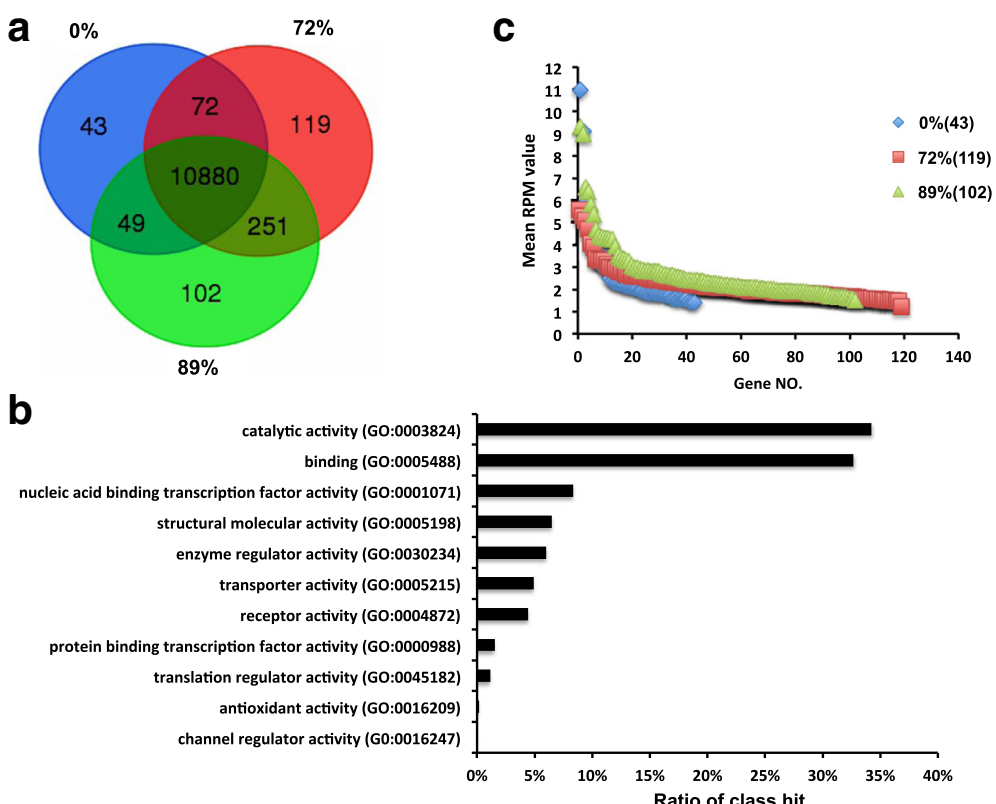

Fig. 1 Dietary differences of the transcriptome profiles among different diets (0\%, 72\% and $89 \%$ grain). a Venn diagram of expressed genes. $\mathbf{b}$ Functional classification of common expressed genes in three diets. $\mathbf{c}$ Expression of diet dependent genes 
diet 102 genes under $89 \%$ grain, their enriched functions were "extracellular matrix organization", "protein catabolic process", respectively. Although the most of these dietary dependent genes were expressed at low level (Fig. 1c) with $\mathrm{RPM}<5$, the expression of 13 genes showed relatively high abundance $(\mathrm{RPM}>5)$ when heifers were fed diets containing $0 \%$ (4 genes), $72 \%$ (3 genes), and $89 \%$ grain (6 genes), respectively (Table 1 ).

\section{The differentially expressed genes in the ruminal} epithelium between low and high grain diets

The PCA plot revealed that the rumen epithelial transcriptome profiles of heifers fed the low grain $(0 \%)$ diet were different than those fed high grain diets $(72 \%$ and 89\%) except one outlier from $89 \%$ diet (Fig. 2a). When the expression of genes was further compared, 562 genes were differentially expressed (DE). Among them, 432 genes showed higher expression (the fold change $(\mathrm{FC})$ in expression $>1.5$ with the false discovery rate $(\mathrm{FDR})<$ 0.05) in the ruminal epithelia of heifers fed the high grain diet compared to those fed the low grain diet (Fig. 2b, Additional file 1 worksheet 1) with 130 from $72 \%$ grain diet, 191 from $89 \%$ grain diet and 111 from both high grain diets (Fig. 2b). These genes were defined as high grain diet enriched (HGD) DE genes. On the other hand, 104 genes had higher expression (the FC in expression $>1.5$ with the FDR $<0.05$ ) in heifers fed the $0 \%$ grain diet comparing to those fed high grain diets with 11 compared with the those fed $72 \%$ grain diet, 57 compared with the those fed $89 \%$ grain diet, and 36 from both high grain diets (Fig. 2c; Additional file 1). These genes were defined as low grain diet enriched (LGD) DE genes. Although, the functional classification showed no difference in terms of the major functions between the HGD and LGD DE genes (Fig. 2d), the highly expressed HGD DE genes were mainly involved in "Paxillin signaling" and "Integrin signaling" pathways, while highly expressed LGD DE genes were enriched to the canonical pathway of "Complement system" and "Interferon signaling", based on DAVID and Ingenuity Pathway Analysis (IPA) functional analysis (Additional file1 worksheets 2 and 3 ).

\section{Variation in responses of heifers during dietary transition from $72 \%$ to $89 \%$ grain diets}

When the ruminal $\mathrm{pH}$ change for each individual animal was further compared using mean ruminal $\mathrm{pH}$ from a previous study [14], mean ruminal $\mathrm{pH}$ became lower in all heifers after the first dietary transition, from $0 \%$ to $72 \%$ grain. However, after second dietary transition, from $72 \%$ to $89 \%$ grain, the mean ruminal $\mathrm{pH}$ of heifers had three patterns: lower, from $6.30 \pm 0.09$ to $5.87 \pm 0.15, P<0.01$ (down group (DG), 5 heifers); similar, from $6.17 \pm 0.25$ to $6.19 \pm 0.25, P=0.27$ (balanced group (BG), 5 heifers); and higher, from $5.84 \pm 0.42$ to $6.35 \pm 0.37, P<0.05$ (up group (UG), 5 heifers) (Fig. 3a). When the acidosis index values $(\mathrm{pH} \cdot \mathrm{min} / \mathrm{kg})$ were further compared, they were increased in DG animals and decreased in UG animals when the diet transitioned from $72 \%$ to $89 \%$ grain (Fig. 3b). The DG and UG heifers were then selected for further transcriptome comparison to identify the genes that may be associated with the potential molecular mechanisms behind such varied responses.

Table 1 Dietary dependent genes in rumen epithelium

\begin{tabular}{|c|c|c|c|c|}
\hline Item & ID & Symbol & Function and description & Mean RPM $\pm S D$ \\
\hline \multirow[t]{4}{*}{$0 \%$ grain (mean RPM > 5) } & ENSBTAG00000008182 & FOSB & $\begin{array}{l}\text { FBJ murine osteosarcoma viral oncogene } \\
\text { homolog B }\end{array}$ & $11.0 \pm 8.6$ \\
\hline & ENSBTAG00000005182 & $B O L A-A$ & $\begin{array}{l}\text { Major histocompatibility complex, class } 1 \text {, } \\
\text { A precursor }\end{array}$ & $9.1 \pm 3.6$ \\
\hline & ENSBTAG00000019234 & BMP6 & Bone morphogenetic protein 6 & $5.9 \pm 4.1$ \\
\hline & ENSBTAG00000015094 & VNN1 & Vanin 1 & $5.2 \pm 3.6$ \\
\hline \multirow[t]{3}{*}{$72 \%$ grain (mean RPM $>5$ ) } & ENSBTAG00000009812 & Novel & C-X-C motif chemokine 6 & $5.6 \pm 5.0$ \\
\hline & ENSBTAG00000006214 & LOXL2 & Lysyl oxidase homolog 2 precursor & $5.3 \pm 1.6$ \\
\hline & ENSBTAG00000006367 & CTGF & Connective tissue growth factor & $5.1 \pm 2.1$ \\
\hline \multirow[t]{6}{*}{$89 \%$ grain (mean RPM > 5) } & ENSBTAG00000003668 & CXorf57 & Chromosome $X$ open reading frame 57 & $9.3 \pm 5.1$ \\
\hline & ENSBTAG00000009144 & Novel & Uncharacterized protein & $9.0 \pm 6.9$ \\
\hline & ENSBTAG00000005244 & RASLIA & RAS-like, family 11 , member A & $6.6 \pm 4.9$ \\
\hline & ENSBTAG00000021272 & $A B C G 1$ & ATP-binding cassette, sub-family $G$, member1 & $6.4 \pm 3.7$ \\
\hline & ENSBTAG00000025340 & CDHR2 & Cadherin-related family member 2 & $5.8 \pm 3.3$ \\
\hline & ENSBTAG000000010423 & LIFR & Leukemia inhibitory factor receptor alpha & $5.4 \pm 2.3$ \\
\hline
\end{tabular}




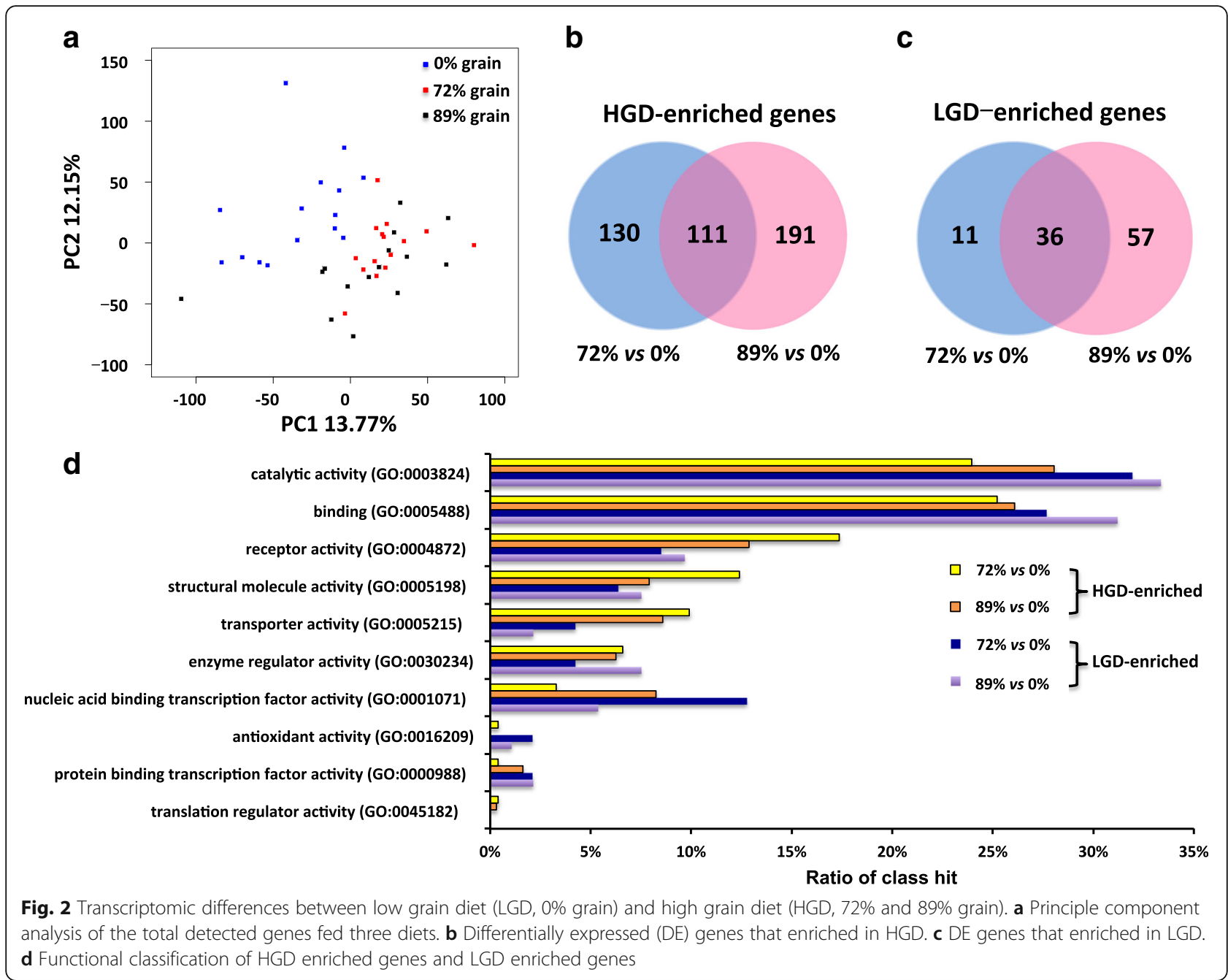

The differentially expressed genes associated with varied responses to ruminal $\mathrm{pH}$ change during the second dietary transition

When the transcriptomes were further compared within DG and UG heifers during the second dietary transition period $(89 \%$ vs. $72 \%)$, the gene expression profiles displayed different changes. In total, $67 \mathrm{DE}$ genes (22 up-regulated and 45 down-regulated; FDR $<0.05, \mathrm{FC}>1.5$ or $<$ -1.5) were found in DG (Additional file 2 worksheet 1), and $285 \mathrm{DE}$ genes (122 up-regulated and 163 downregulated; $\mathrm{FDR}<0.05, \mathrm{FC}>1.5$ or $<-1.5$ ) were found in UG (Additional file 2 worksheet 2). Among them, 23 DE genes were commonly detected from both DG and UG, while 44 and $262 \mathrm{DE}$ genes were only found in DG and UG, respectively (Fig. 3c). Most of the common DE genes $(n=18)$ showed the same change trend in both DG and UG (14 genes were down regulated and 4 gene were up regulated), while expression of $5 \mathrm{DE}$ genes exhibited opposite change trend between the two groups. In particular, the expression of $C Y P 1 A 1$ and $C Y P 1 B 1$ were up regulated in UG ( $\mathrm{FC}=1.8$ and 1.6) but were down regulated in DG $(\mathrm{FC}=-1.7$ and -2.0$)$, whereas the expression of $C H A C 1$, $C D S N$ and $K L K 10$ were up regulated in DG $(\mathrm{FC}=2.3,2.1$ and 1.5) but were down regulated in UG $(\mathrm{FC}=-2.0,-1.4$ and -3.3) (Fig. 3d).

Functional analysis of DE genes detected for DG and UG during the second dietary transition

The functional prediction of $67 \mathrm{DE}$ genes in the DG using IPA revealed that their most relevant functions were "Immune response of leukocytes", "Attraction of phagocytes", and "Cell movement of leukocytes" $(P<$ 0.05 ), and were inhibited when fed $89 \%$ grain diet (Zscore $=-2.2,-2.2$ and -2.0 , respectively) (Table 2). In addition, the function of "Quantity of $\mathrm{Ca}^{2+}$ ", "Fatty acid metabolism", and "Mobilization of $\mathrm{Ca}^{2+}$ " were also inhibited (Z-score $<-1.5)$ for DG after second dietary transition (Table 2). The predicted function of the down-regulated DE genes (using DAVID $n=45$ ) in the 


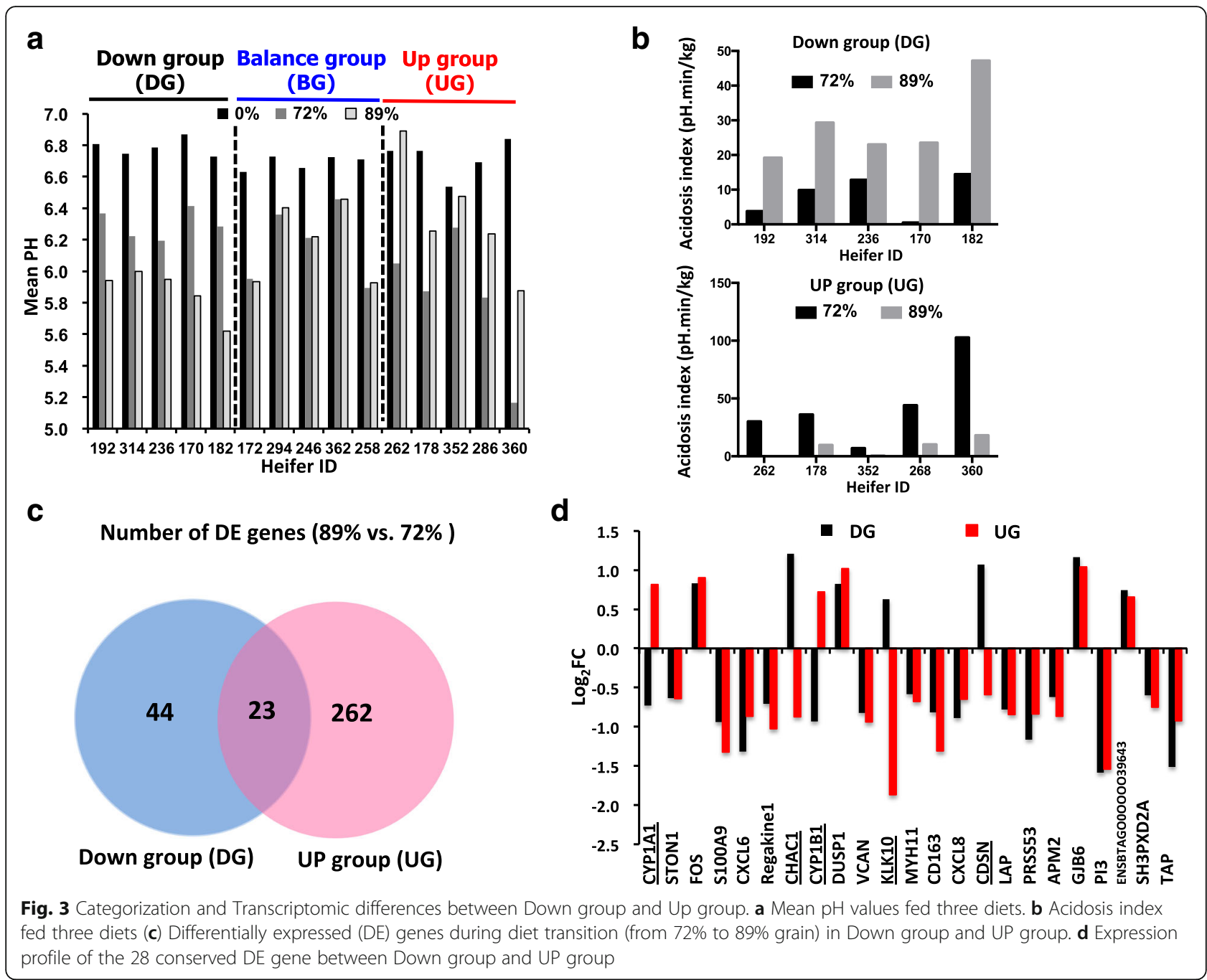

DG was related to "Innate immune response" $(P<$ 0.0001) (Table 3).

For 285 DE genes in the UG, functions of "Concentration of lipid" and "Proliferation of epithelial cells" were inhibited (Z-score $=-2.0$, and -1.8 , respectively), while the functions of "Cell cycle progression" and "Transmigration of phagocytes" were activated (Z-score $=2.2$ and 2.0, respectively) after second dietary transition (Table 2). The function prediction of down-regulated genes $(n=163)$ in UG using DAVID revealed functions related to activity in cell proliferation, such as "Cell division", "Mitotic metaphase plate congression", "Chromosome segregation", and "mitotic nuclear division" $(P<0.001)$ (Table 3). Moreover, the enriched function of upregulated genes $(n=122)$ in UG were "Positive regulation of JUN kinase activity", "Toxin metabolic process", "Cholesterol homeostasis", and "Drug metabolic process" $(P<0.05)$ (Table 3$)$.

Further functional pathways analysis using IPA showed eight DE genes in DG were found to be involved in two different pathways including "Role of pattern recognition receptors in recognition of bacteria and viruses" (Zscore $=-2.0)$ and "TREM1 signaling" (Z-score $=-2.0$ ) (Table 4). For the UG, the "PTEN signaling" pathway was inhibited (Z-score $=-2.0$ ), while the pathways of "NF- $\mathrm{B}$ signaling", "PDGF signaling", and "Cell cycle: G2/M DNA damage checkpoint regulation" were activated (Z-score $=2.4,2.2$ and 2.2, respectively). The KEGG pathways of those DE genes enriched by DAVID showed similar results (Table 5). Briefly, eight DE genes in DG were found to be involved in three KEGG pathways including "Staphylococcus aureus infection" and "complement and coagulation cascades" (5 down regulated genes), and "T cell receptor signaling pathway" (3 upregulated genes) (Table 5). In the UG, 25 DE genes were enriched in ten different KEGG pathways. Among them, the downregulated genes were involved in four pathways including "Cell cycle", "Glycolysis/Gluconeogenesis", "FoxO signaling pathway", "p53 signaling pathway", and "Mineral absorption"; the upregulated genes 
Table 2 Enriched functions of DE genes in Down and Up group using IPA (89\% grain vs. 72\% grain)

\begin{tabular}{|c|c|c|c|}
\hline Enriched functions & $p$-Value & Z-score & Molecules \\
\hline \multicolumn{4}{|l|}{ Down group } \\
\hline Immune response of leukocytes & $1.14 \mathrm{E}-02$ & -2.2 & C3, CXCL8, FCGR2B, IL1B, ISG15 \\
\hline Attraction of phagocytes & 7.33E-05 & -2.2 & C3, CXCL5, CXCL8, ILIB, VCAN \\
\hline Attraction of myeloid cells & 5.73E-05 & -2.2 & C3, CXCL5, CXCL8, IL1B, VCAN \\
\hline Cell movement of leukocytes & 4.17E-02 & -2.0 & $\begin{array}{l}\text { C3, CXCL5, CXCL8, FOS, IL1B, } \\
\text { S100A9, VCAN }\end{array}$ \\
\hline Infection of cells & $2.35 \mathrm{E}-03$ & -2.0 & $C 2, C 3, E I F 2 A K 2, F C G R 2 B$ \\
\hline Stimulation of leukocytes & $1.18 \mathrm{E}-02$ & -2.0 & $C 3, C X C L 5, C X C L 8, I L 1 B$ \\
\hline Quantity of $\mathrm{Ca}^{2+}$ & 4.61E-03 & -2.0 & C3, CXCL8, IL1B, S100A9 \\
\hline Adhesion of neutrophils & $2.42 \mathrm{E}-03$ & -2.0 & C3, CXCL8, IL1B, S100A9 \\
\hline Apoptosis of macrophages & $3.86 \mathrm{E}-03$ & -2.0 & EIF2AK2, FOS, IL1B, ISG15 \\
\hline Activation of granulocytes & $5.11 \mathrm{E}-03$ & -1.9 & $C 3, C X C L 8, F C G R 2 B, I L 1 B$ \\
\hline Viral Infection & 5.73E-05 & -1.9 & $\begin{array}{l}\text { C2, C3, CXCL8, EGR1, EIF2AK2, } \\
\text { FCGR2B, IL1B, MX1, S100A9 }\end{array}$ \\
\hline Binding of leukocytes & $1.39 \mathrm{E}-02$ & -1.8 & $\begin{array}{l}\text { A2M, C3, CXCL8, FCGR2B, IL1B, } \\
\text { S100A9 }\end{array}$ \\
\hline Fatty acid metabolism & $1.78 \mathrm{E}-03$ & -1.8 & $\begin{array}{l}\text { CXCL8, CYP3A4, FABP4, FCGR2B, } \\
\text { IL1B }\end{array}$ \\
\hline Apoptosis of leukocytes & $1.14 \mathrm{E}-02$ & -1.8 & $\begin{array}{l}\text { CXCL8, EGR1, EIF2AK2, FCGR2B, } \\
\text { FOS, IL1B, ISG15 }\end{array}$ \\
\hline Cell death of immune cells & $1.78 \mathrm{E}-03$ & -1.7 & $\begin{array}{l}\text { C3, CXCL8, EGR1, EIF2AK2, } \\
\text { FABP4, FCGR2B, FOS, IL1B, ISG15, } \\
\text { MX1, MYH11 }\end{array}$ \\
\hline Degranulation of phagocytes & 1.57E-04 & -1.7 & $\begin{array}{l}\text { C3, CXCL8, DUSP1, FCGR2B, FOS, } \\
\text { IL1B, S100A9 }\end{array}$ \\
\hline Adhesion of immune cells & 2.77E-02 & -1.6 & A2M, C3, CXCL8, IL1B, S100A9 \\
\hline Binding of professional phagocytic cells & $5.75 \mathrm{E}-03$ & -1.6 & $A 2 M, C 3, C X C L 8, I L 1 B, S 100 A 9$ \\
\hline Mobilization of $\mathrm{Ca}^{2+}$ & $1.14 \mathrm{E}-02$ & -1.6 & $A 2 M, C 3, C X C L 8, F C G R 2 B$ \\
\hline Migration of phagocytes & $5.28 \mathrm{E}-03$ & -1.6 & $\begin{array}{l}\text { C3, CXCL5, CXCL8, IL1B, S100A9, } \\
\text { VCAN }\end{array}$ \\
\hline Migration of granulocytes & $2.35 \mathrm{E}-03$ & -1.5 & C3, CXCL5, CXCL8, IL1B, S100A9 \\
\hline \multicolumn{4}{|l|}{ Up group } \\
\hline Concentration of lipid & $8.12 \mathrm{E}-02$ & -2.0 & $\begin{array}{l}\text { ABCA1, CXCL8, CYP1A1, CYP1B1, } \\
\text { S100A9 }\end{array}$ \\
\hline Proliferation of epithelial cells & $9.40 \mathrm{E}-02$ & -1.8 & $\begin{array}{l}\text { CAV1, CDC25B, CXCL8, EDN1, } \\
\text { FLT1, FOS, FRS2, GLI1, KRAS, } \\
\text { KRT16, MKI67, NR3C1, ODC1, } \\
\text { PTHLH, SULF2 }\end{array}$ \\
\hline Recruitment of neutrophils & $7.13 \mathrm{E}-02$ & -1.6 & $\begin{array}{l}\text { CAV1, CXCL2, CXCL5, CXCL8, } \\
\text { CYPIA1, CYP1B1, EDN1, P2RY2 }\end{array}$ \\
\hline Quantity of T lymphocytes & 1.15E-01 & 1.5 & $\begin{array}{l}\text { ACKR4, BIRC5, CCNB2, CD48, } \\
\text { FOS, IL6ST, KRAS, LGALS1, } \\
\text { MYH11, MYSM1, NR3C1, PTTG1, } \\
\text { TACC3, TGFBR1, TSC1, XIAP }\end{array}$ \\
\hline Differentiation of epithelial cells & $7.13 \mathrm{E}-02$ & 1.7 & $\begin{array}{l}\text { AURKB, CAV1, DSG1, E2F8, EDN1, } \\
\text { GNAQ, KRAS, KRT14, KRT16, PLK1, } \\
\text { PTHLH, SH3PXD2A }\end{array}$ \\
\hline Transmigration of myeloid cells & $7.13 \mathrm{E}-02$ & 2.0 & CXCL5, CXCL8, ITGAV, LGALS1 \\
\hline Transmigration of phagocytes & $9.78 \mathrm{E}-02$ & 2.0 & CXCL5, CXCL8, ITGAV, LGALSI \\
\hline Cell cycle progression & 7.13E-02 & 2.2 & $\begin{array}{l}\text { BIRC5, CDC25B, CKAP2, FOS, } \\
\text { KRAS, LGALS4, MAP3K1, PLK1, XIAP }\end{array}$ \\
\hline
\end{tabular}


Table 3 Enriched functions of DE genes in the Down and Up group using DAVID (89\% grain vs. 72\% grain)

\begin{tabular}{|c|c|c|}
\hline GO terms & $P$ value & Molecules \\
\hline \multicolumn{3}{|l|}{ Down Group } \\
\hline \multicolumn{3}{|l|}{ Down-regulated genes $(n=45)$} \\
\hline GO:0045087 innate immune response & $8.2 \mathrm{E}-05$ & EIF2AK2, MX1, S100A9, C2, NLRC5, C1QB \\
\hline GO:0042742 defense response to bacterium & $1.2 \mathrm{E}-04$ & ISG15, CXCL5, TAP \\
\hline GO:0006958 complement activation, classical pathway & 2.7E-04 & $C 3, C 2, C 1 Q B$ \\
\hline GO:0051607 defense response to virus & $9.8 \mathrm{E}-04$ & OASIY, ISG15, MXI, NLRC5 \\
\hline $\begin{array}{l}\text { GO:0045071 negative regulation of viral genome } \\
\text { replication }\end{array}$ & $1.2 \mathrm{E}-03$ & EIF2AK2, ISG15, MX1 \\
\hline GO:0009636 response to toxic substance & 2.4E-03 & EIF2QK2, CYP1A1, CYP1B1 \\
\hline GO:0009404 toxin metabolic process & 1.1. $\mathrm{E}-02$ & CYP1A1, CYP1B1 \\
\hline $\begin{array}{l}\text { GO:2,000,427 positive regulation of apoptotic cell } \\
\text { clearance }\end{array}$ & $1.5 \mathrm{E}-02$ & $C 3, C 2$ \\
\hline GO:0006956 complement activation & $1.8 \mathrm{E}-02$ & $C 3, C 2$ \\
\hline GO:0034340 response to type I interferon & $2.2 \mathrm{E}-02$ & ISG15, MX1 \\
\hline GO:0006955 immune response & $2.2 \mathrm{E}-02$ & OASIY, CXCL5, LOC504773 \\
\hline GO:0070098 chemokine-mediated signaling pathway & 4.7E-02 & CXCL5, LOC504773 \\
\hline \multicolumn{3}{|l|}{ Up-regulated genes $(n=22)$} \\
\hline GO:0035914 skeletal muscle cell differentiation & $3.2 \mathrm{E}-02$ & EGRI, FOS \\
\hline \multicolumn{3}{|l|}{ Up Group } \\
\hline \multicolumn{3}{|l|}{ Down-regulated genes $(n=163)$} \\
\hline GO:0051301 cell division & 4.4E-09 & $\begin{array}{l}\text { SKA3, ASPM, CKS2, PTTG1, CCNB1, BIRC5, } \\
\text { CCNB2, AURKA, SPC24, NCAPH, UBE2C, } \\
\text { CCNA2, CDCA3, SPDL1, TPX2 }\end{array}$ \\
\hline GO:0007080 mitotic metaphase plate congression & $6.0 \mathrm{E}-05$ & KIF22, KIFC1, CDCA8, KIF2C, CCNB1, SPDL1 \\
\hline GO:0007018 microtubule-based movement & $1.1 \mathrm{E}-04$ & KIF22, KIFC1, KIF2C, KIF11, KIF20A, CENPE \\
\hline GO:0007059 chromosome segregation & $3.1 \mathrm{E}-04$ & SKA3, SLC25A5, KIF11, CENPT, BIRC5, HJURP \\
\hline GO:0007067 mitotic nuclear division & 3.8E-04 & PLK1, SKA3, ASPM, CCNA2, PTTG1, CCNB2, NUF2, SPC24 \\
\hline GO:0031577 spindle checkpoint & $6.1 \mathrm{E}-04$ & $A \cup R K B, B I R C 5, S P D L 1$ \\
\hline GO:0045143 homologous chromosome segregation & $6.1 \mathrm{E}-04$ & PLK1, ESPL1, PTTG1 \\
\hline GO:0000070 mitotic sister chromatid segregation & $1.4 \mathrm{E}-03$ & PLK1, CDCA8, ESPL1, SPAG5 \\
\hline $\begin{array}{l}\text { GO:0051988 regulation of attachment of spindle } \\
\text { microtubules to kinetochore }\end{array}$ & $2.0 \mathrm{E}-03$ & RACGAP1, ECT2, SPAG5 \\
\hline GO:0007052 mitotic spindle organization & 2.7E-03 & $A \cup R K B, C C N B 1, N D C 80, A \cup R K A$ \\
\hline GO:0000281 mitotic cytokinesis & 4.1E-03 & PLK1, RACGAP1, KIF20A, CKAP2 \\
\hline GO:0090307 mitotic spindle assembly & $5.3 \mathrm{E}-03$ & KIFC1, KIF11, BIRC5, TPX2 \\
\hline GO:0034501 protein localization to kinetochore & $5.4 \mathrm{E}-03$ & $A \cup R K B, S P D L 1, B \cup B 1 B$ \\
\hline GO:0010628 positive regulation of gene expression & $6.7 \mathrm{E}-03$ & MAPK11, CAV1, ACTA2, FN1, ACTG2, VIM \\
\hline GO:0000910 cytokinesis & $8.0 \mathrm{E}-03$ & CIT, KIF2OA, BIRC5, ECT2 \\
\hline GO:0007094 mitotic spindle assembly checkpoint & $1.2 \mathrm{E}-02$ & $P L K 1, B \cup B 1 B, B \cup B 1$ \\
\hline GO:0071346 cellular response to interferon-gamma & $1.9 \mathrm{E}-02$ & SLC26A6, GAPDH, LOC504773 \\
\hline GO:0001578 microtubule bundle formation & $2.4 \mathrm{E}-02$ & PLK1, KIF20A, TPPP3 \\
\hline GO:0006096 glycolytic process & 2.7E-02 & GAPDH, ENO1, ENO2 \\
\hline GO:0035606 peptidyl-cysteine S-trans-nitrosylation & $2.8 \mathrm{E}-02$ & GAPDH, S100A9 \\
\hline GO:0006816 calcium ion transport & $3.9 \mathrm{E}-02$ & CAV1, ANXA6, CACNA1G \\
\hline GO:0045931 positive regulation of mitotic cell cycle & $3.9 \mathrm{E}-02$ & CCNB1, BIRC5, CDC25B \\
\hline
\end{tabular}

Up-regulated genes $(n=122)$ 
Table 3 Enriched functions of DE genes in the Down and Up group using DAVID (89\% grain vs. 72\% grain) (Continued)

\begin{tabular}{lll}
\hline GO terms & $P$ value & Molecules \\
\hline GO:0043507 positive regulation of JUN kinase activity & $1.4 \mathrm{E}-02$ & FZD5, EDN1, EPHA4 \\
GO:2,001,237 negative regulation of extrinsic apoptotic & $2.6 \mathrm{E}-02$ & PHIP, ITGAV, TGFBR1 \\
signaling pathway & & \\
GO:0009404 toxin metabolic process & $2.9 \mathrm{E}-02$ & CYP1A1, CYP1B1 \\
GO:0018406 protein C-linked glycosylation via 2'-alpha- & $2.9 \mathrm{E}-02$ & DPY19L3, DPY19L4 \\
mannosyl-L-tryptophan & & \\
GO:0002904 positive regulation of B cell apoptotic process & $2.9 \mathrm{E}-02$ & FNIP1, CD24 \\
GO:0042632 cholesterol homeostasis & $3.0 \mathrm{E}-02$ & CD24, ABCA1, EPHX2 \\
GO:0017144 drug metabolic process & $3.8 \mathrm{E}-02$ & CYP1A1, FMO5 \\
GO:0045944 positive regulation of transcription from RNA & $4.1 \mathrm{E}-02$ & PHIP, TET2, FZD5, EDN1, CCNT1, FOS, NRIP1, MYSM1, PCGF5 \\
polymerase II promoter & & \\
\hline
\end{tabular}

were mainly related to metabolic pathways including "tryptophan metabolism", "Retinol metabolism", "Drug metabolism - cytochrome P450", and "metabolism of xenobiotics by cytochrome P450" (Table 5).

\section{Upstream regulator and network analysis of DE genes} detected for DG and UG during the second dietary transition Four upstream regulators were identified in regulating the DE genes in DG, including Interferon gamma (IFN $)$, transmembrane protein 173 (TMEM173), toll like receptor 3 (TLR3), and tumor necrosis factor (TNF) (Fig. 4a). For the DE genes in UG, nine upstream regulators were identified with colony stimulating factor 2 (CSF2) and prostaglandin E receptor 2 (PTGER2) being the hub nodes (Fig. 4b). Two and three networks were enriched (score $>20$ ) in DG and UG, and the related functions were immune response and cell cycle, respectively (Additional file 2 worksheets 3 and 4).

\section{Differential expression of genes involved in lipid transport, metabolism and intracellular homeostasis regulation in DG and UG}

Among above genes identified in DG and UG animals, the expression of 14 lipid transport and 13 fatty acid

Table 4 Enriched ingenuity canonical pathways of DE genes in the Down and Up group using IPA (89\% grain vs. 72\% grain)

\begin{tabular}{|c|c|c|c|}
\hline Ingenuity canonical pathways & -log ( $p$-Value) & z-score & Molecules \\
\hline \multicolumn{4}{|l|}{ Down group } \\
\hline $\begin{array}{l}\text { Role of Pattern Recognition Receptors in } \\
\text { Recognition of Bacteria and Viruses }\end{array}$ & $3.42 \mathrm{E}+00$ & -2.0 & CXCL8, OAS1, C3, IL1B, C1QB, EIF2AK2 \\
\hline TREM1 Signaling & $2.59 \mathrm{E}+00$ & -2.0 & $C X C L 8, N L R C 5, I L 1 B, F C G R 2 B$ \\
\hline \multicolumn{4}{|l|}{ Up group } \\
\hline PTEN Signaling & $6.06 \mathrm{E}-01$ & -2.0 & TGFBR1, NTRK2, FLT1, KRAS \\
\hline Renin-Angiotensin Signaling & $9.28 \mathrm{E}-01$ & 1.6 & FOS, MAP3K1, GNAQ, KRAS, MAPK11, FRS2 \\
\hline IL-8 Signaling & 8.71E-01 & 1.6 & RAB11FIP2, CXCL8, FOS, FLT1, ITGAV, KRAS, FRS2 \\
\hline ERK5 Signaling & $9.19 \mathrm{E}-01$ & 2.0 & ILGST, FOS, GNAQ, KRAS \\
\hline JAK/Stat Signaling & 8.00E-01 & 2.0 & FOS, GNAQ, KRAS, FRS2 \\
\hline NF-KB Activation by Viruses & 7.90E-01 & 2.0 & MAP3K1, ITGAV, KRAS, FRS2 \\
\hline VEGF Family Ligand-Receptor Interactions & 7.76E-01 & 2.0 & FOS, FLT1, KRAS, FRS2 \\
\hline Rac Signaling & $6.17 \mathrm{E}-01$ & 2.0 & MAP3K1, PIKFYVE, KRAS, FRS2 \\
\hline PKC $\theta$ Signaling in T Lymphocytes & $5.46 \mathrm{E}-01$ & 2.0 & FOS, MAP3K1, KRAS, FRS2 \\
\hline $\begin{array}{l}\text { Role of NFAT in Regulation of the Immune } \\
\text { Response }\end{array}$ & 4.09E-01 & 2.0 & FOS, GNAQ, KRAS, FRS2 \\
\hline $\begin{array}{l}\text { Cell Cycle: G2/M DNA Damage Checkpoint } \\
\text { Regulation }\end{array}$ & $2.15 E+00$ & 2.2 & CDC25B, CKS2, CCNB2, PLK1, AURKA, CCNB1 \\
\hline PDGF Signaling & $9.28 \mathrm{E}-01$ & 2.2 & FOS, MAP3K1, CAV1, KRAS, FRS2 \\
\hline NF-KB Signaling & 7.60E-01 & 2.4 & TGFBR1, NTRK2, FLT1, MAP3K1, KRAS, FRS2 \\
\hline
\end{tabular}


Table 5 Enriched KEEG pathways of DE genes in the Down and Up group using DAVID (89\% grain vs. 72\% grain)

\begin{tabular}{lll}
\hline Term & $p$ value & Molecules \\
\hline Down Group & & \\
Down-regulated genes $(n=45)$ & $1.5 \mathrm{E}-04$ & FCGR2B, C3, C2, C1QB \\
bta05150: Staphylococcus aureus infection & $2.9 \mathrm{E}-04$ & A2M, C3, C2, C1QB \\
bta04610: Complement and coagulation cascades & & \\
Up-regulated genes ( $n=22)$ & $9.34 \mathrm{E}-03$ & CD3D, CD3G, FOS \\
bta04660: T cell receptor signaling pathway & & \\
Up Group & & \\
Down-regulated genes ( $n=163)$ & $1.07 \mathrm{E}-05$ & PLK1, CCNA2, ESPL1, CDC20, PTTG1, CCNB1, \\
bta04110:Cell cycle & $2.02 \mathrm{E}-02$ & GAPDH, LDHB, ENO2, ENO1 \\
bta00010:Glycolysis/Gluconeogenesis & $4.35 \mathrm{E}-02$ & PLK1, MAPK11, BNIP3, CCNB1, CCNB2 \\
bta04068:FoxO signaling pathway & GTSE1, RRM2, CCNB1, CCNB2 \\
bta04115:p53 signaling pathway & $4.37 \mathrm{E}-02$ & SLC26A6, MT1E, MT2A \\
bta04978:Mineral absorption & $4.48 \mathrm{E}-02$ & \\
Up-regulated genes ( $n=122)$ & & AOX1, CYP1A1, CYP1B1 \\
bta00380: Tryptophan metabolism & $2.77 \mathrm{E}-02$ & CYP1A1, ADH6, AOX1 \\
bta00830:Retinol metabolism & $3.00 \mathrm{E}-02$ & ADH6, AOX1, FMO5 \\
bta00982:Drug metabolism - cytochrome P450 & $3.73 \mathrm{E}-02$ & CYP1A1, ADH6, CYP1B1 \\
bta00980:Metabolism of xenobiotics by cytochrome P450 & $4.52 \mathrm{E}-02$ & \\
\hline
\end{tabular}

metabolism related genes $(\mathrm{RPM}>1$ in 5 heifers of at least one diet) were further investigated in the rumen epithelia (Fig. 5). In DG heifers, the expression of SMCT1 $(P<0.1)$ was lower while the expression of FABP4 $(P<0.05)$, HMGCL $(P<0.1)$, and SREBF2 $(P<$ 0.1 ) was higher when fed the $89 \%$ grain diet than the $72 \%$ grain diet. In the UG heifers, the expression of FABP5 $(P<0.05), A B C A 2(P<0.05)$, and $A B C A 7(P<$
0.1), ACAT2 $(P<0.05)$, HMGCS1 $(P<0.1)$, HMGCR $(P$ $<0.1)$, and FDPS $(P<0.1)$ was lower, whereas the expression of $A B C A 1 \quad(P<0.05)$, and $A B C A 5(P<0.1)$ was higher when fed the $89 \%$ grain diet than the $72 \%$ grain diet (Fig. 5a \& b). In addition, the expression pattern of genes associated with ion transportation in rumen epithelium was further investigated. The expression of NHES $(P<0.1)$, and MCT4 $(P<0.05)$ was decreased in

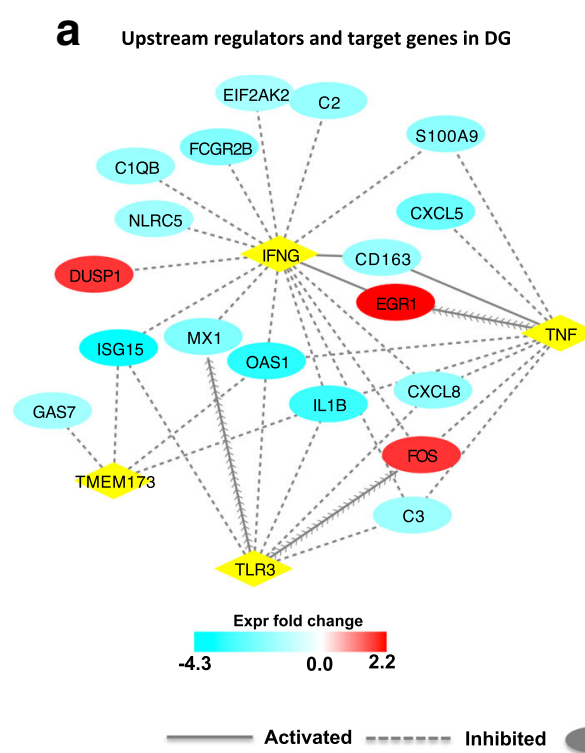

b Upstream regulators and target genes in UG

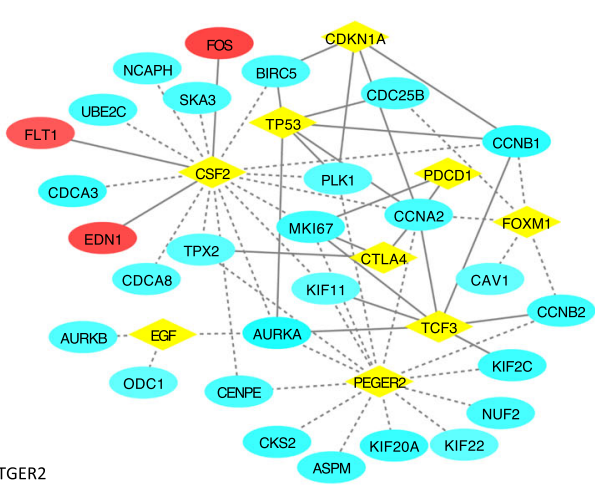

PTGER2

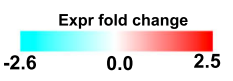

Target genes Upstream regulator

Fig. 4 Upstream regulator analysis of DE genes in Down group (DG) and Up group (UG). a Upstream regulators and target genes in DG. b Upstream regulators and target genes in UG 

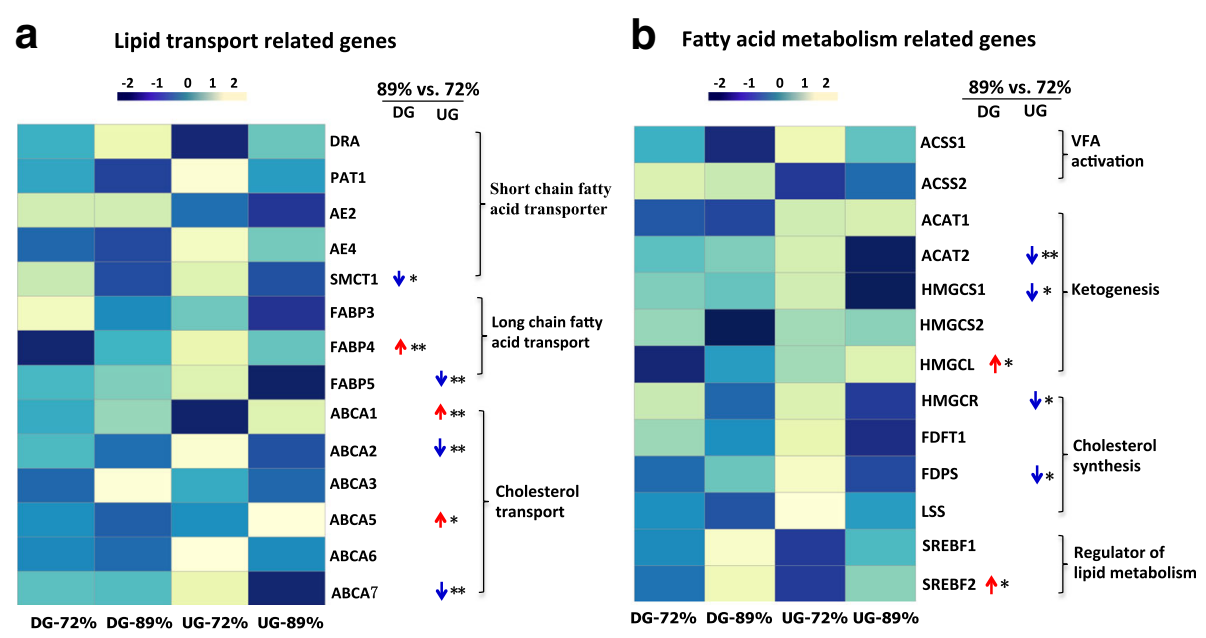

Fig. 5 The patterns of lipid transport and fatty acid metabolism related genes expression during diet transition (from $72 \%$ to $89 \%$ grain) in DG and UG. a The pattern of lipid transport related genes expression. $\mathbf{b}$ The pattern of fatty acid metabolism related genes expression. The legend represents the RPM value scaled by rows, the blue means highly expressed in the $72 \%$ grain and yellow means highly expressed in the $89 \%$ grain. The data were analyzed by T-test, ${ }^{*}$ indicated $P<0.1$, ** indicated $P<0.05$, and ${ }^{* * *}$ indicated $P<0.01$. $\downarrow$ means decreased and $\uparrow$ means increased when the diet transitioned from $72 \%$ grain to $89 \%$ grain within each group

DG, while the expression of NHE3 $(P<0.05)$ was increased in UG after the second dietary transition (Additional file 3: Figure S1). Further validation of the differential expression using reverse transcription quantitative real-time PCR (RT-qPCR) showed the expression of FABP4, ABCA1, NHE3 and ACAT2 was consistent as detected with the RNA-seq data (Additional file 4: Figure S2).

In addition, 70 SNPs were detected in 9 genes that relate to lipid transport, metabolism and intracellular homeostasis regulation (Additional file 2 worksheet 5), and association analysis (Fisher's exact test) of detected single nucleotide polymorphisms (SNPs) indicated that one intronic SNP (g.46834311A $>$ G) in FABP4 was associated with the varied expression in the ruminal epithelial tissue between UG and DG animals $(P<0.1$, Additional file 5: Figure S3).

\section{Discussion}

The comparative analysis of the whole transcriptome profiles revealed the high grain diet can alter the gene expression in the rumen epithelia. Although gene expression of rumen epithelial tissues in response to high concentrate diets have been studied, most of the previous studies have focused on selected genes using $\mathrm{qPCR} /$ microarray [15-17] and/or compared the difference using different groups of animals $[11,18]$ as well as to study the dairy cows with small numbers of animals [15]. This is the first study that applied RNA-seq based genome-wide transcriptome analysis to study the global gene expression changes in ruminal epithelia under three dietary conditions for the same individual using 15 beef heifers. Furthermore, our effort is the first to identify the varied expression pattern changes in the rumen epithelia of animals having different $\mathrm{pH}$ change patterns with the gradual high grain transition from $72 \%$ to $89 \%$ grain.

It has been known that feeding highly fermentable diets could be associated with the prevalence of ruminal acidosis $[6,19]$. When ruminal $\mathrm{pH}$ duration time, a widely used diagnostic parameter for the acidosis [20, 21], was analyzed, 8 out of 15 heifers had $\mathrm{pH}$ below 5.8 for longer than $5.4 \mathrm{~h} / \mathrm{d}$ when fed $89 \%$ grain, suggesting they may have developed subacute acidosis. In contrast to these heifers, the others had lower ruminal $\mathrm{pH}$ duration time when fed the same diet, emphasizing that response variation existed among individuals as previously reported [11, 12], which was reflected by our observation of DG and UG heifers. Together with the mean of continuous ruminal $\mathrm{pH}$, it suggests that each heifer may have developed a different adaptive mechanism, with DG responding less favorably than UG. To understand the mechanism behind such individual variation, the following discussion will be mainly focused on the gene expression pattern variation between in DG and in UG animals.

The most enriched networks of DE genes in DG and UG were related to immune response and cell cycle, respectively, suggesting that the innate immune function might be differently regulated between DG and UG heifers during second dietary transition. Although scarce information is available about the organization of the mucosal immune system in the rumen epithelia, the 
Langerhans cells were identified in epithelium of bovine forestomach [22] and bovine forestomachs could receive, elaborate and produce signals and mediators of the innate immune response [23]. Here, we found the innate immune response related functions such as "Immune response of leukocytes", "Attraction of phagocytes", and "Cell movement of leukocytes" were inhibited in DG but not in UG, suggesting that innate immune response could be one of the mechanisms involved in epithelial adaptation to high grain diet. In addition, the most abundant GO categories enriched by downregulated DE genes in DG were related to immune response. Decreased expression of immune-related genes (including IL-6, IL-10, and interferon) had been reported in ruminal epithelia of lambs when fed concentrate starter [24]. Similar results were found in DG, in particular, the expression of genes encoding complement component 2/3 (C2 / C3), C-X-C chemokine ligand 5 (CXCL5), and NOD-like receptor C5 (NLRC5) were downregulated during the diet transition from $72 \%$ to $89 \%$ grain. The $C 2 / C 3$ plays central role in the complement system and contributes to innate immunity [25]. It's well known that epithelial cells recognized microbial components through means of Toll-like and NOD-like receptors (TLRs and NLRs) $[26,27]$. The decreased expression of NLRC5 might limit the recognition of commensal bacteria, which is essential for the development and function of the immune system in the mucosal and peripheral districts [28]. Indeed, the epimural bacterial population differed between acidosis tolerant and susceptible beef cattle and the expression of TLR2 and TLR4 were lower in susceptible cattle [29]. The previous study also showed varied microbial changes associated with the ruminal epithelia for the same animals [14]. The observed potential inhibited innate immune responses further support our previous speculation that host-microbial interactions could play a role in affecting the host adaptation to the high grain diet transition. The lowered innate immune function may negatively affect the rumen function which result in the persistent decrease of ruminal $\mathrm{pH}$ during the second transition in DG.

In addition, the enriched pathway of "G2/M DNA damage checkpoint regulation" was activated through downregulation of genes related to cell cycle progression in UG [30-32], including cell division cycle 25 homolog B (CDC25B), cyclin-dependent kinases regulatory subunit 2 (CKS2), cyclin $\mathrm{B} 1 / 2(C C N B 1 / 2)$, polo like kinase 1 (PLK1), and aurora kinase A (AURKA), suggesting the enhanced cell cycle arrest in UG. Furthermore, the enriched KEGG pathway of "p53 signaling" in UG also indicates the higher cell arrest since the activated p53 could activate cell repair and apoptosis procedure to induce cell cycle arrest $[33,34]$. Moreover, the pathway of
"Metabolism of xenobiotics by cytochrome P450" was enriched in UG heifers. The higher expression of three genes involved in this pathway (alcohol dehydrogenase 6 (ADH6), cytochrome p450 family 1 subfamily A member $1(C Y P 1 A 1)$, and subfamily $B$ member $1(C Y P 1 B 1)$ ) in UG suggest the higher capacity to remove the ruminal toxins in these animals since these genes have been reported to be involved in the metabolism of the some ruminal toxins, such as ethanol and serials of xenobiotics $[35,36]$. Taking these together, we speculate that the UG animals may have more activated innate immune responses, cell repair function and toxin removal activities to maintain the ruminal health during the second dietary transition. The upstream regulator analysis further supports our speculation since the identified IFNG, TNF, TLR3, and TMEM173 regulate genes involved in the immune function, while the CSF2 and PTGER2 regulate genes involved in cell proliferation.

Considering the fact that VFAs absorption accounts for up to $50 \%$ of the ruminal buffering capacity [7], the increase in intra-epithelial uptake and metabolism of SCFAs could promote the uptake of SCFAs and a stabilization of ruminal $\mathrm{pH}$ [8]. We hypothesized that the expression patterns of genes involved in SCFAs absorption and metabolism may also play an important role in individualized animal rumen $\mathrm{pH}$ changes when diet was switched from $72 \%$ grain to $89 \%$ grain. The expression of sodium dependent monocarboxylate transporters 1 (SMCT1) tended to decrease in the DG heifers but no difference was observed in the UG heifers during the second transition period. The SMCT1 and SMCT2 play important roles in SCFA transport in addition to the $\mathrm{SCFA}^{-} / \mathrm{HCO}_{3}^{-}$exchanger system $[37,38]$. These results suggest that the absorption of SCFA via the SMCT1 in the DG heifers might be decreased, which may partly account for the lower mean $\mathrm{pH}$ in DG heifers. In addition to SCFA absorption, SCFA metabolism could also impact on the rumen $\mathrm{pH}$ environment. In this study, we focused on the genes involved in butyrate catabolism in the rumen epithelia, which occurs via ketogenesis and beta-oxidation to produce ketone bodies $[39,40]$. The expression of ACATs and HMGCS, the genes encoding the rate-limiting enzymes for ketogenesis [41], decreased in UG after the second transition period. However, the expression of $H M G C L$ increased in DG for the same dietary transition period, suggesting that UG heifers have decreased ketogenesis in the epithelia comparing to DG.

In addition, the expression of genes involved in fatty acids and lipids transport and metabolism were also found to be different between DG and UG heifers. For example, the increased expression of FABP4 was observed in DG heifers but not in UG heifers when diet transitioned from $72 \%$ to $89 \%$ grain. Fatty acid binding 
proteins (FABPs) usually bind to fatty acids and/or lipids to transport and deliver them to different sites for utilization [42]. It has been reported that increased expression of FABP4 was responsible for the enhanced macrophage lipid accumulation in diabetic patients of human, and this effect was further paralleled with elevated intracellular total cholesterol and triacylglycerol levels [43]. Therefore, the increased expression of FABP4 in the ruminal epithelia of DG heifers suggest the intracellular lipid accumulation, which could be partially supported by the tended increased expression of sterol regulatory element binding protein 2 (SREBF2) in the same group of animals. The SREBF family plays important role in regulating cholesterogenic and lipogenic gene expression in the bovine liver and mammary glands $[44,45]$, while the isoform SREBF2 preferentially activates cholesterol biosynthesis [46]. Although cholesterol synthesis pathway has not been well characterized in the ruminal epithelia, it's reported that butyrate can be used as a precursor for cholesterol biosynthesis [46, 47]. Compared with DG, the expression of cholesterol synthesis related genes (HMGCS1, HMGCR and FDPS) was decreased in UG heifers when diet transitioned from $72 \%$ to $89 \%$ grain. Steele et al. [15] also reported the coordinated downregulation of these genes in the rumen epithelia of dairy cows when fed a $65 \%$ grain diet from the first to third week. These suggest that the intracellular cholesterol synthesis could also be one of the mechanisms for the individualized responses when adapted to the high grain diet. It is known that cholesterol is the key component of the plasma membrane and plays crucial role in cellular signal transduction, cell growth, cell polarization, migration, and survival [48]. The cellular content of cholesterol is determined not only by the synthesis but also by the efficiency of influx and efflux [48] transportation of them and their derivatives through $\mathrm{ABC}$ transporters [49, 50]. Among them, ABCA1 has been most intensively studied, which could regulate and maintain cellular cholesterol homeostasis through transferring cholesterol to high-density lipoprotein in various types of cells $[51,52]$. In this study, the increased expression of $A B C A 1$ was observed in the UG, but not in DG heifers. In addition, the function of "Concentration of lipid" was inhibited in the UG heifers, suggesting the UG might be more efficient in exporting cholesterol out of rumen epithelia and have less stored cholesterol. Taken together, our results suggest that the deposition of cholesterol in addition to cholesterol synthesis in the rumen epithelia is also one of the mechanisms to attribute to the variation observed between DG and UG animals (Additional file 6: Figure S4). Moreover, previous studies showed that increased intracellular cholesterol could inhibit various ion channels in the biological membrane of human [53, 54], and high cholesterol is closely related to membrane permeability and inflammation in human [55]. Therefore, the inhibited function of "Quantity of $\mathrm{Ca}^{2+"}$ and innate immunity in the DG animals could be resulted from higher concentration intracellular content of cholesterol during the dietary adaptation from $72 \%$ to $89 \%$ grain. Further measuring the cholesterol concentration in rumen epithelia is needed to verify the findings obtained from our transcriptome analysis.

Furthermore, this study also identified the genetic variation of genes related to lipid transport and metabolism. Association analysis indicated that 1 SNP (g.46834311A > G) in FABP4 was associated with the varied ruminal $\mathrm{pH}$ response between DG and UG heifers, which may be attributed to the changes in the expression of this gene between DG and UG animal after the secondary diet transition. This suggests that the genetic background between "Up" and "Down" heifers could be one of the factors that lead to the observed varied gene expression. To determine the role of genetic variation in regulating the genes involved in different responses to high fermentable dietary transition, future researches on genotyping of large population with varied phenotypic measures (ruminal $\mathrm{pH}$, duration and area of ruminal $\mathrm{pH}$ below 5.8) using genome wide association study (GWAS) are needed.

\section{Conclusions}

This is the first study that has identified varied molecular mechanisms may contribute to the individual variations in response to the high grain adaptation through analyzing the genome wide transcriptome in the ruminal epithelia of beef heifers. Understanding the whole transcriptome is essential to reveal the molecular events within cells, and to elucidate the mechanisms regulating the adaptive function and physiology of rumen in response to dietary changes. Overall, we suggest that the different genes that controlled immune function, cellular repair function, and intracellular homeostasis (cholesterol) might be the molecular mechanism accounting for individual variation in the response to gradual transition to a high grain diet. As summarized in Fig. 6, feeding high fermentable diet usually results in increased concentration of ruminal VFA and toxins, which may induce the cell damage for both DG and UG. At transcriptomic level, the innate immunity, cell cycle, toxin metabolism, and cholesterol homeostasis was differentially regulated in DG and UG. In the DG, the inhibited innate immune response and accumulated cholesterol in the cells may aggravate the cell damage and finally decrease the cellular stability and homeostasis. However, in the UG, cell cycle arrest and xenobiotic metabolism was activated for repairing and protecting the cell damage, which contributes to increase cellular stability and homeostasis. It is noticeable that, gene expression can be regulated at both transcriptional and post-transcriptional level, and even post-translational 


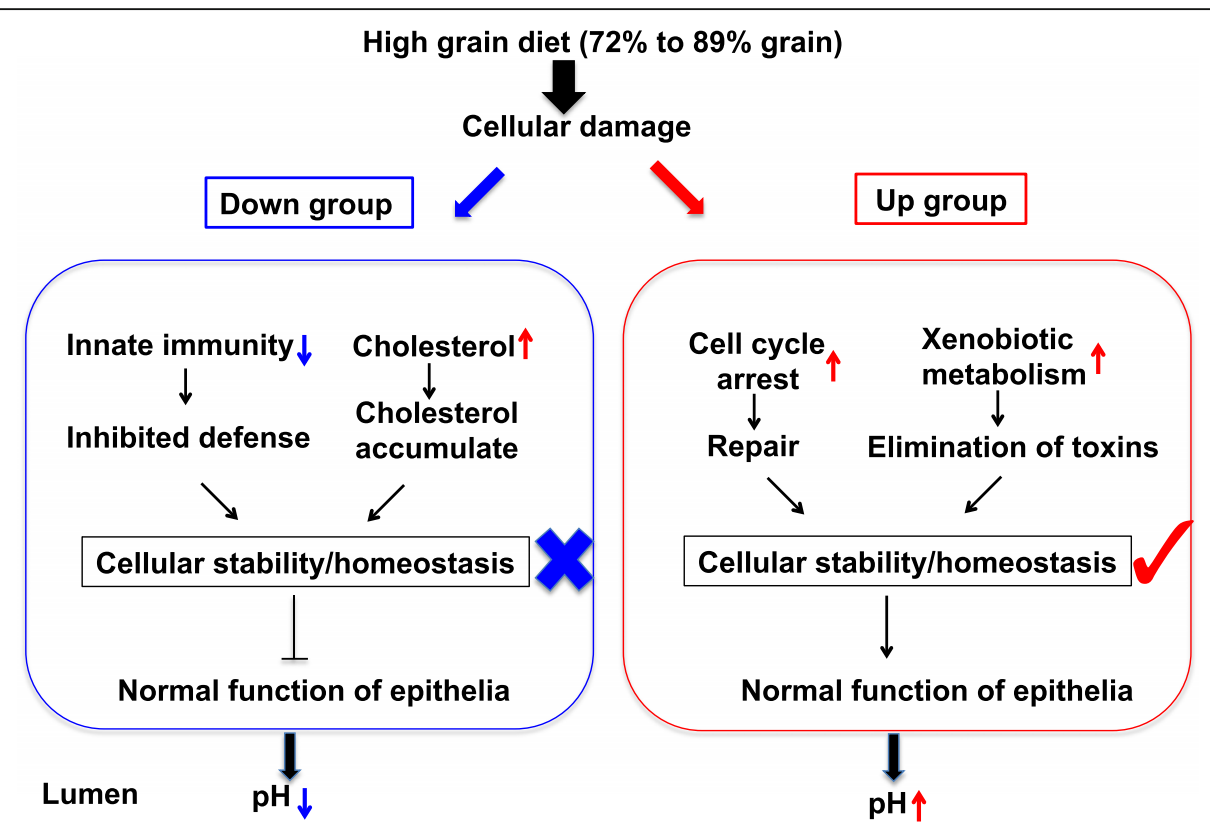

Fig. 6 Illustrative comparison of the gene networks related to distinct adaptation between Down group and Up group. $\downarrow$ means decreased and $\uparrow$ means increased when the diet transitioned from $72 \%$ grain to $89 \%$ grain within each group

modifications can also affect the activity of protein [56, 57]. Future studies on the protein, enzyme and metabolites are needed to comprehensively determine the molecular mechanisms of individualized host response to high grain feeding. Regardless, the transcriptomic information from this study provides the informative clue for further study such as the identified gene networks, upstream regulators (IFNG, TNF, TLR3, CSF2, and PTGER2), and FABP4-A/G SNP could be potential gene and genetic markers for selecting cattle with maintained ruminal $\mathrm{pH}$ during high fermentable diet transition.

\section{Methods}

\section{Experimental design and sample collection}

Twenty-four Angus-Hereford cross-bred yearling heifers (about 8 months old, weighing $244 \mathrm{~kg}$ to $369 \mathrm{~kg}$ ) from the University of Alberta Kinsella Ranch (Kinsella, AB) were used for this study. Detailed information on the animal study, diets, feeding of diets, and intake has been reported previously [14]. Briefly, heifers were blocked into 1 of 6 blocks based on body weight and, within block, were randomly assigned to 1 of 2 treatments. Each block consisted of 1 heifer assigned to the control $(\mathrm{CON}, n=6))$ treatment and 3 heifers assigned to the rapid grain adaptation (RA) treatment $(n=18)$. Unequal weighting of the treatment assignment was used as more variation was expected for the RA treatment than for the CON (Bevans et al., 2005). All the RA heifers we randomly assigned to a gradual grain transition treatment $(n=18)$ throughout a 29-d experiment period.
Briefly, heifers were initially fed a diet containing 0\% grain (days 1 to 4 ) and transitioned to a final diet containing $89 \%$ grain using the following intermediate diets: $40 \%$ grain (days 5 to 8 ), $60 \%$ grain (days 9 to 12 ), $72 \%$ grain (days 13 to 16 ), $85 \%$ grain (days 17 to 20 ), and $89 \%$ grain (days 21 to 29). Rumen papillae biopsies were collected from the ventral sac of the rumen when the heifers were fed $0 \%$ grain on day 3 (the 3rd day of a 4day feeding period), $72 \%$ grain on day 15 (the 3 rd day of a 4-day feeding period), and $89 \%$ grain on day 26 (the 6th day of a 9-day feeding period). The biopsies were immediately washed with sterile $0.01 \mathrm{M}$ phosphatebuffered saline buffer $(\mathrm{pH}$ 6.8) and transferred into RNA-later solution (Invitrogen, Carlsbad, CA). After being kept at $4{ }^{\circ} \mathrm{C}$ overnight, all the samples were stored at $-20{ }^{\circ} \mathrm{C}$ for further analysis. To identify the molecular mechanisms responsible for the varied response to a gradual high grain diet transition, the ruminal papillae samples from RA heifers were used in this study and due to three of animals did not have biopsy samples for all three treatment periods, only fifteen animals (under three dietary conditions) were subjected to transcriptome analysis.

\section{Ruminal pH measurement}

Ruminal $\mathrm{pH}$ was measured using a stand-alone submersible continuous ruminal $\mathrm{pH}$ measurement system following the procedures as reported previously [58]. Briefly, the $\mathrm{pH}$ meter was inserted into the rumen through a cannula on day 1 and was removed every four days for standardization. 
Ruminal pH data were collected every $30 \mathrm{~s}$ for each diet treatment $(0 \%, 72 \%$ and $89 \%$ grain diet), and the daily minimum, mean, and maximum $\mathrm{pH}$ values were determined. In addition, the number of episodes that ruminal $\mathrm{pH}$ was below the threshold of 5.8, as well as the duration and area of these episodes were calculated. The area was calculated as $\mathrm{pH}$ unit $\times \mathrm{min} /$ day when the ruminal $\mathrm{pH}$ was lower than 5.8 and the duration was calculated the time (h/day) that ruminal $\mathrm{pH}$ was below 5.8 in the heifers.

The acidosis index, an indicator of the severity of ruminal acidosis, was calculated by the following formula: acidosis index $(\mathrm{pH} \cdot \mathrm{min} / \mathrm{kg})=$ area that ruminal pH below 5.8 ( $\mathrm{min}) /$ dry matter intake $(\mathrm{kg})$ [18].

\section{RNA isolation}

Ruminal papillae samples were ground while immersed in liquid nitrogen using a frozen mortar and pestle prior to RNA extraction. Total RNA was extracted from $50 \mathrm{mg}$ of the resultant papillae tissue powder using Trizol reagent (Invitrogen, CA, USA) following the manufacturer's instructions. The quantity and quality of the RNA were determined using Qubit 2.0 Fluorometer (Invitrogen, Carlsbad, CA) and Agilent 2100 Bioanalyzer (Agilent Technologies, Santa Clara, CA), respectively. The samples with RNA integrity number (RIN) greater than 8.0 were used for library construction.

\section{RNA-seq library construction and sequencing}

The RNA-seq libraries were constructed using the TruSeq mRNA Sample Preparation Kit (Illumina, San Diego, CA) according to the manufacturer's instructions. Total RNA (1.0 $\mu \mathrm{g}$ each) from 45 samples (each with a unique index) were mixed and pooled for transcriptome sequencing (paired ends sequencing, $100 \mathrm{bp}$ ) at Génome Québec (Montréal, Canada) using the Illumina HiSeq 2000 system (Illumina) with all 45 samples loaded on a single chip with 9 samples per lane: each lane contains samples from $0 \%, 72 \%$, and $89 \%$ grain diet. All reads were demultiplexed according to their index sequences with CASAVA version 1.8 (Illumina) and reads that did not pass the Illumina chastity filter were discarded.

\section{RNA-seq reads mapping and annotation}

RNA-seq reads were aligned to the bovine genome (UMD 3.1) using Tophat 2.0.10 with default parameters [59]. The number of reads mapped to each gene was counted by htseq-count (http://htseq.readthedocs.io/) based on the annotation from the ENSEMBL (http:// uswest.ensembl.org/) bovine gene annotation software (v75.30). The expression levels of mRNA in each library was calculated by normalizing reads to reads per million (RPM) by the following formula: $R P M=$ (gene reads number/total mapped reads number per library) $\times$ $1,000,000$.

\section{Identification of differentially expressed genes}

Among the detected genes, those that were detected in at least one sampling point with more than 1 RPM in 15 heifers were considered as expressed genes. Then, differentially expressed (DE) genes were investigated by using bioinformatics tool edgeR [60]. The DE genes affected by diet were identified by comparing any two diets $(72 \%$ vs. $0 \% ; 89 \%$ vs. $0 \%)(n=15)$. After that, the individual DE genes were identified by comparing the two high grain diets $(89 \%$ vs. $72 \%)$ of each group $(n=10)$. The DE mRNA were identified by false discovery rate (FDR) < 0.05 based on Benjamini and Hochberg multiple testing correction [61] as well as a fold change $>1.5$ or $<-1.5$. The expression of four DE genes that related to lipid synthesis (FABP4), lipid transport $(A B C A 1), \mathrm{Na}^{+} / \mathrm{H}^{+}$exchange (NHE3), and ketogenesis (ACAT2) was detected using RT-qPCR.

\section{Quantitative real-time PCR (qRT-PCR) analysis}

A total of 4 genes were selected to validate the DE genes and the primers used were listed in Additional file 7: Table S1. The RT-qPCR reactions were performed with SYBR Green (Fast SYBR ${ }^{\bullet}$ Green Master Mix; Applied Biosystems) using StepOnePlus ${ }^{\mathrm{TM}}$ Real-Time PCR System (Applied Biosystems, Foster City, CA, USA) with the fast cycle and the following program: $20 \mathrm{~s}$ pre-denaturalization at $95^{\circ} \mathrm{C}$, followed by 40 cycles of $3 \mathrm{~s}$ denaturation at $95^{\circ} \mathrm{C}$ and $30 \mathrm{~s}$ annealing and extension at $60^{\circ} \mathrm{C}$. Gene expression values were normalized to reference gene of $\beta$-actin in the same sample. The relative changes in each gene expression were calculated using the $2^{-\Delta \Delta C T}$ (cycle threshold, CT) method.

\section{Functional analysis}

The gene list analysis tool in PANTHER classification system was used for gene ontology (GO) terms analysis of the commonly and highly expressed genes among $0 \%$, $72 \%$, and $89 \%$ die, and the ratio was calculated according to the number of 'hits' to the terms over the total number of 'class hits' [62]. The functional analysis of dietary enriched/DE genes was performed by Database for Annotation, Visualization and Integrated Discovery (DAVID, http://david.abcc.ncifcrf.gov) [63], and Ingenuity pathway analysis (IPA, Ingenuity Systems, www.ingenuity.com). In details, we used all detected genes in rumen epithelia (11,516 genes) as background of DAVID for functional analysis (Additional file 1), and selected the database of digestive tract tissues (including forestomach, stomach, small intestine, and large intestine) and epithelial/immune cells for IPA analysis in this study. A threshold of $P<0.05$ for DAVID and Benjamini and Hochberg 
multiple testing correction $P<0.05$ for IPA, and molecules number $>2$ was applied to enrich significant biological functions and pathways. The absolute value of Z-score > 1.5 was used as cutoff for activation or inhibition of biological functions and pathways, and the cutoff for networks was score $>20$.

\section{Systematic analysis of lipid transport and fatty acid metabolism related genes in DG and UG during diet transition}

The expression of sodium-linked monocarboxylate transporter (SMCT1 and SMCT2), proton-linked monocarboxylate transporter (MCT1, MCT2, MCT3, and $M C T 4$ ), long chain fatty acid transporter (FABP1, $F A B P 2, F A B P 3, F A B P 4, F A B P 5, F A B P 6, F A B P 7, F A B P 9$, and $F A B P 12)$, cholesterol efflux protein (ABCA1, $A B C A 2, A B C A 3, A B C A 4, A B C A 5, A B C A 6, A B C A 7$, $A B C A 9, A B C A 10, A B C A 12$, and $A B C A 13)$, bicarbonate transporter (PAT1), anion exchanger ( $A E 2, A E 3$, $A E 4, D R A)$ were analyzed by T-test in rumen epithelia of DG and UG heifers when the diet switched from $72 \%$ to $89 \%$ grain.

The SCFA metabolism related genes including acylCoA synthetases (ACSS1, ACSS2 and ACSS3) that activate the volatile fatty acids, acetyl-CoA acetyl transferases (ACAT1 and ACAT2) and 3-hydroxy, 3methylglutaryl CoA synthase (HMGCS1) that convert acetyl-CoA to 3-hydroxy, 3-methylglutaryl CoA (HMGCoA) [47],HMG-CoA lyase (HMGCL) which catalyze the synthesis of ketone bodies acetoacetate and $\beta$ hydroxybutyrate [47, 64], cholesterolgenic genes: HMGCoA reductase (HMGCR), farnesyl-diphosphate farnesyltransferase 1 (FDFT1), farnesyl diphosphate synthase (FDPS), and lanosterol synthase (LSS), and sterol regulatory element binding transcription factors (SREBF1 and SREBF2) were analyzed by T-test in rumen epithelia of DG and UG heifers during diet transition (from $72 \%$ to $89 \%$ ).

\section{SNP analysis}

The 5 UG and 5 DG heifers were chose for SNP analysis. RNA-Seq reads of ruminal papillae fed $0 \%, 72 \%$ and $89 \%$ grain diets were first combined for each heifer to increase read coverage. Then the SNP calling was performed using VarScan2 [65]. The minimum based quality of reads was 15 , minimum reads depth at a position to call a SNP was 8 , and the minimum variant allele frequency threshold was 0.1 . The association between alleles and varied ruminal $\mathrm{pH}$ response was determined by Fisher exact test, and $P<0.1$ was considered as significance difference. The SNP was discarded when less than 2 reads mapped to that location in at least one heifer in this study.

\section{Additional files}

Additional file 1: Differentially expressed genes with higher expression in cattle fed low grain diets (72\% vs. $0 \%$ and $89 \%$ vs. $0 \%)$; Functional annotation of HGD and LGD enriched genes using DAVID (72\% vs. $0 \%$ and $89 \%$ vs. 0\%) (worksheet 2); Functional annotation of HGD and LGD enriched genes using IPA (72\% vs. 0\% and $89 \%$ vs. 0\%) (worksheet 3). (XLSX 465 kb)

Additional file 2: Differentially expressed genes in Down group (89\% vs. 72\% grain) (worksheet 1); Differentially expressed genes in Up group (89\% vs. 72\% grain) (worksheet 2); Networks enriched using DE genes in Down group ( $89 \%$ vs. $72 \%$ grain) (worksheet 3); Networks enriched using DE genes in Up group (89\% vs. 72\% grain) (worksheet 4); The detected SNPs (worksheet 5). (XLSX 67 kb)

Additional file 3: Figure S1. The patterns of ions transportation related genes expression in DG and UP. The legend represents the RPM value scaled by rows, the blue means highly expressed in the $72 \%$ grain and yellow means highly expressed in the $89 \%$ grain. The data were analyzed by T-test, ${ }^{*}$ indicated $P<0.1$, ** indicated $P<0.05$, and ${ }^{* * *}$ indicated $P<$ 0.01. $\downarrow$ means decreased and $\uparrow$ means increased when the diet transitioned from $72 \%$ grain to $89 \%$ grain within each group. (PDF $59 \mathrm{~kb}$ )

Additional file 4: Figure S2. RT-qPCR validation of selected target genes identified by RNA-seq. The gene expressions detected by RT-qPCR are shown by line graphs on the top and values are shown on the right Y-axis as relative abundance. The gene expressions detected by RNA-seq are shown by bar graphs on the bottom and values are shown on the left $Y$-axis as $\log _{2}$ RPM. The data were analyzed by T-test, ${ }^{*}$ indicated $P<$ 0.1 , ** indicated $P<0.05$. (PDF $105 \mathrm{~kb}$ )

Additional file 5: Figure S3. Single nucleotide polymorphisms (SNPS) associated with the varied ruminal $\mathrm{pH}$ response. (A) Fisher exact test of the association between SNPs and varied ruminal $\mathrm{pH}$ response. (B) The sequences of the SNP ( $g 46,834,311 \mathrm{~A}>\mathrm{G}$ ). (PDF $81 \mathrm{~kb}$ )

Additional file 6: Figure S4. Illustrative comparison of the gene networks related to fatty acid transport and metabolism between Down group and Up group. $\downarrow$ means decreased and $\uparrow$ means increased when the diet transitioned from $72 \%$ grain to $89 \%$ grain within. (PDF $131 \mathrm{~kb}$ )

Additional file 7: Table S1. Primers sequences used for RT-qPCR. (DOCX $61 \mathrm{~kb})$

\section{Abbreviations}

ABCA: Cholesterol efflux protein; ACAT: Acetyl-CoA acetyl transferases;"; ACSS: Acyl-CoA synthetases; ADH6: Alcohol dehydrogenase 6; AE2: Anion exchanger; AURKA: Aurora kinase A; C2/C3: Complement component 2/3; CCNB1/2: Cyclin B1/2; CDC25B: Cell division cycle 25 homolog B; CDSN: Corneodesmosin; CHAC1: ChaC glutathione specific gammaglutamylcyclotransferase 1; CKS2: Cyclin-dependent kinases regulatory subunit 2; CON: Control; CSF2: Colony stimulating factor 2; CXCL5: C-X-C chemokine ligand 5; CYP1A1: Cytochrome p450 family 1 subfamily A member 1; CYP1B1: Subfamily B member 1; DAVID: Database for Annotation, Visualization and Integrated Discovery; DE: Differentially expressed; DG: Down group; DRA: MHC class II DR alpha chain; FABP: Fatty acid binding protein; FC: Fold change; FDFT1: Farnesyl-diphosphate farnesyl-transferase 1; FDPS: Farnesyl diphosphate synthase; FDR: False discovery rate; GO: Gene ontology; GWAS: Genome wide association study; HGD: High grain diet; HMGCL: 3-methylglutaryl CoA lyase; HMGCR: 3-methylglutaryl CoA reductase; HMGCS: 3-hydroxy, 3-methylglutaryl CoA synthase; IFNg: Interferon gamma; IL: Interleukin; IPA: Ingenuity Pathway Analysis; KEGG: Kyoto Encyclopedia of Genes and Genomes; KLK10: kallikrein related peptidase 10; LGD: Low grain diet; LSS: lanosterol synthase; MCT: Proton-linked monocarboxylate transporter; NHE: Sodium hydrogen exchanger; NLRC5: NLR FAMILY card domain containing 5; NLRC5: NOD-like receptor C5; NLRs: NOD-like receptors; PAT1: Bicarbonate transporter; PCA: Principal component analysis; PDGF: Platelet-derived growth factor; PLK1: Polo like kinase 1;

PTGER2: Prostaglandin E receptor 2; RA: Rapid grain adaptation; RIN: RNA integrity number; RNA: Ribonucleic acid; RPM: Reads per million; RTqPCR: Reverse transcription quantitative real-time PCR; SCFA: Short chain fatty acid; SMCT1: Sodium dependent monocarboxylate transporters; SNP: Single nucleotide polymorphisms; SREBF2: Sterol regulatory element 
binding protein 2; TLR3: Toll like receptor 3; TMEM173: Transmembrane protein; TNF: Tumor necrosis factor; TREM1: Triggering receptor expressed on myeloid cells 1; UG: Up group

\section{Acknowledgements}

The authors acknowledge the technical assistance by X. Sun for the RNA-seq library construction and the members of Drs. Guan and Oba labs for the sampling

\section{Funding}

This study is supported by Alberta Livestock Meat Agency (ALMA 2011F129R and ALMA2015P008R), NSERC discovery grant for L. L. Guan and Chinese International Postdoctoral Exchange Fellowship Program (20140020) for K. Zhao.

\section{Availability of data and materials}

All the sequencing data sets supporting the results in the current study have been deposited in the publicly available NCBI's Gene Expression Omnibus Database (http://www.ncbi.nlm.nih.gov/geo/) (GSE89874).

\section{Authors' contributions}

KZ did the data analysis and draft the manuscript. LLG, GBP, and MO designed the experiments and revised the manuscript critically for important intellectual content. YHC collected the samples and constructed the libraries. All authors contributed to the writing of the manuscript and approved the submission.

\section{Ethics approval}

The animal study was approved by the Livestock Animal Care Committee of the University of Alberta (protocol number OBA077) and all procedures were conducted following the guidelines of Canadian Council on Animal Care.

\section{Consent for publication}

Not applicable.

\section{Competing interests}

The authors declare that they have no competing interests.

\section{Publisher's Note}

Springer Nature remains neutral with regard to jurisdictional claims in published maps and institutional affiliations.

\section{Author details \\ 'Department of Agricultural, Food and Nutritional Sciences, University of Alberta, 416 F Agr/For, Edmonton, AB T6G2P5, Canada. ${ }^{2}$ College of Food Engineering and Nutritional Science, Shaanxi Normal University, Xi'an, Shaanxi 710119, China. ${ }^{3}$ Department of Animal and Poultry Science, University of Saskatchewan, Saskatoon S7N5A8, Canada.}

\section{Received: 28 November 2016 Accepted: 17 November 2017} Published online: 19 December 2017

\section{References}

1. Wierenga KT, McAllister TA, Gibb DJ, Chaves AV, Okine EK, Beauchemin KA, Oba M. Evaluation of triticale dried distillers grains with solubles as a substitute for barley grain and barley silage in feedlot finishing diets. J Anim Sci. 2010;88(9):3018-29.

2. Bevans DW, Beauchemin KA, Schwartzkopf-Genswein KS, McKinnon Jנ, McAllister TA. Effect of rapid or gradual grain adaptation on subacute acidosis and feed intake by feedlot cattle. J Anim Sci. 2005;83(5):1116-32.

3. Nocek JE. Bovine acidosis: implications on laminitis. J Dairy Sci. 1997;80(5): 1005-28.

4. Ametaj BN, Zebli Q, lqbal S. Nutrition, microbiota, and endotoxin-related diseases in dairy cows. R Bras Zootec. 2010;39:433-44.

5. Gressley TF, Hall MB, Armentano LE. Ruminant nutrition symposium: productivity, digestion, and health responses to hindgut acidosis in ruminants. J Anim Sci. 2011;89(4):1120-30.

6. Owens FN, Secrist DS, Hill WJ, Gill DR. Acidosis in cattle: a review. J Anim Sci. 1998:76(1):275-86

7. Gäbel G, Bestmann M, Martens H. Influences of diet, short-chain fatty-acids, lactate and chloride on bicarbonate movement across the reticulorumen wall of sheep. J Vet Med A. 1991;38(7):523-9.

8. Penner GB, Aschenbach JR, Gäbel G, Rackwitz R, Oba M. Epithelial capacity for apical uptake of short chain fatty acids is a key determinant for intraruminal $\mathrm{pH}$ and the susceptibility to subacute ruminal acidosis in sheep. J Nutr. 2009:139(9):1714-20.

9. Aschenbach JR, Penner GB, Stumpff F, Gäbel G. Ruminant nutrition symposium: role of fermentation acid absorption in the regulation of ruminal pH. J Anim Sci. 2011;89(4):1092-107.

10. Castillo-Lopez E, Wiese BI, Hendrick S, McKinnon JJ, McAllister TA, Beauchemin KA, Penner GB. Incidence, prevalence, severity, and risk factors for ruminal acidosis in feedlot steers during backgrounding, diet transition, and finishing. J Anim Sci. 2014;92(7):3053-63.

11. Schlau N, Guan LL, Oba M. The relationship between rumen acidosis resistance and expression of genes involved in regulation of intracellular pH and butyrate metabolism of ruminal epithelial cells in steers. J Dairy Sci. 2012:95(10):5866-75

12. Mohammed R, Stevenson DM, Weimer PJ, Penner GB, Beauchemin KA. Individual animal variability in ruminal bacterial communities and ruminal acidosis in primiparous Holstein cows during the periparturient period. J Dairy Sci. 2012:95(11):6716-30.

13. Humer E, Ghareeb K, Harder H, Mickdam E, Khol-Parisini A, Zebeli Q. Peripartal changes in reticuloruminal $\mathrm{pH}$ and temperature in dairy cows differing in the susceptibility to subacute rumen acidosis. J Dairy Sci. 2015;98(12):8788-99.

14. Chen YH, Penner GB, Li MJ, Oba M, Guan LL. Changes in bacterial diversity associated with epithelial tissue in the beef cow rumen during the transition to a high-grain diet. Appl Environ Microbiol. 2011;77(16):5770-81.

15. Steele MA, Vandervoort G, AlZahal O, Hook SE, Matthews JC, McBride BW. Rumen epithelial adaptation to high-grain diets involves the coordinated regulation of genes involved in cholesterol homeostasis. Physiol Genomics. 2011;43(6):308-16.

16. Steele MA, Dionissopoulos L, AlZahal O, Doelman J, McBride BW. Rumen epithelial adaptation to ruminal acidosis in lactating cattle involves the coordinated expression of insulin-like growth factor-binding proteins and a cholesterolgenic enzyme. J Dairy Sci. 2012;95(1):318-27.

17. Oba M, Mewis $J \mathrm{~L}$, Zhining Z. Effects of ruminal doses of sucrose, lactose, and corn starch on ruminal fermentation and expression of genes in ruminal epithelial cells. J Dairy Sci. 2015:98(1):586-94.

18. Penner GB, Taniguchi M, Guan LL, Beauchemin KA, Oba M. Effect of dietary forage to concentrate ratio on volatile fatty acid absorption and the expression of genes related to volatile fatty acid absorption and metabolism in ruminal tissue. J Dairy Sci. 2009;92(6):2767-81.

19. Kleen JL, Hooijer GA, Rehage J, Noordhuizen JPTM. Subacute ruminal acidosis (SARA): a review. J Vet Med A Physiol Pathol Clin Med. 2003;50(8):406-14.

20. Gozho GN, Plaizier JC, Krause DO, Kennedy AD, Wittenberg KM. Subacute ruminal acidosis induces ruminal lipopolysaccharide endotoxin release and triggers an inflammatory response. J Dairy Sci. 2005;88(4):1399-403.

21. Penner GB, Oba M, Gäbel G, Aschenbach JR. A single mild episode of subacute ruminal acidosis does not affect ruminal barrier function in the short term. J Dairy Sci. 2010;93(10):4838-45.

22. Gerneke WH. Langerhans cells in epithelium of bovine forestomach - their role in primary immune response. J S Afr Vet Assoc. 1977;48(3):187-92.

23. Trevisi E, Amadori M, Riva F, Bertoni G, Bani P. Evaluation of innate immune responses in bovine forestomachs. Res Vet Sci. 2014;96(1):69-78.

24. Liu J, Bian G, Sun D, Zhu W, Mao S. Starter feeding altered ruminal epithelial bacterial communities and some key immune-related genes' expression before weaning in lambs. J Anim Sci. 2017:95(2):910-21.

25. Lubbers $R$, van Essen MF, van Kooten C, Trouw LA. Production of complement components by cells of the immune system. Clin Exp Immunol. 2017;188(2):183-94.

26. Rakoff-Nahoum S, Paglino J, Eslami-Varzaneh F, Edberg S, Medzhitov R. Recognition of commensal microflora by toll-like receptors is required for intestinal homeostasis. Cell. 2004;118(2):229-41.

27. Uehara A, Fujimoto Y, Fukase K, Takada H. Various human epithelial cells express functional toll-like receptors, NOD1 and NOD2 to produce antimicrobial peptides, but not proinflammatory cytokines. Mol Immunol. 2007; 44(12):3100-11.

28. Macpherson AJ, Harris NL. Interactions between commensal intestinal bacteria and the immune system. Nat Rev Immunol. 2004;4:478-85.

29. Chen YH, Oba M, Guan LL. Variation of bacterial communities and expression of toll-like receptor genes in the rumen of steers differing in susceptibility to subacute ruminal acidosis. Vet Microbiol. 2012:159(3-4):451-9.

30. Sur S, Agrawal DK. Phosphatases and kinases regulating CDC25 activity in the cell cycle: clinical implications of CDC25 overexpression and potential treatment strategies. Mol Cell Biochem. 2016;416(1):33-46. 
31. Lobjois V, Jullien D, Bouche JP, Ducommun B. The polo-like kinase 1 regulates CDC25B-dependent mitosis entry. Biochim Biophys Acta. 2009;1793(3):462-8.

32. Durlacher CT, Li ZL, Chen XW, He ZX, Zhou SF. An update on the pharmacokinetics and pharmacodynamics of alisertib, a selective aurora kinase a inhibitor. Clin Exp Pharmacol Physiol. 2016;43(6):585-601.

33. Levine AJ. p53, the cellular gatekeeper for growth and division. Cell. 1997;88(3):323-31.

34. Monte M, Benetti R, Buscemi G, Sandy P, Del Sal G, Schneider C. The cell cycle-regulated protein human GTSE-1 controls DNA damage-induced apoptosis by affecting p53 function. J Biol Chem. 2003;278(32):30356-64.

35. Nelson DR, Koymans L, Kamataki T, Stegeman JJ, Feyereisen R, Waxman DJ, Waterman MR, Gotoh O, Coon MJ, Estabrook RW, Gunsalus IC, Nebert DW. P450 superfamily: update on new sequences, gene mapping, accession numbers and nomenclature. Pharmacogenetics. 1996;6(1):1-42.

36. Höög JO, Strömberg P, Hedberg JJ, Griffiths WJ. The mammalian alcohol dehydrogenases interact in several metabolic pathways. Chem Biol Interact. 2003:143:175-81.

37. Miyauchi S, Gopal E, Fei YJ, Ganapathy V. Functional identification of SLC5A8, a tumor suppressor down-regulated in colon cancer, as a $\mathrm{Na}^{+}$-coupled transporter for short-chain fatty acids. J Biol Chem. 2004;279(14):13293-6.

38. Ganapathy V, Thangaraju M, Gopal E, Martin PM, Itagaki S, Miyauchi S, Prasad PD. Sodium-coupled monocarboxylate transporters in normal tissues and in cancer. AAPS J. 2008;10(1):193-9.

39. Britton R, Krehbiel C. Nutrient metabolism by gut tissues. J Dairy Sci. 1993;76(7):2125-31.

40. Kristensen NB, Harmon DL. Splanchnic metabolism of volatile fatty acids absorbed from the washed reticulorumen of steers. J Anim Sci. 2004;82(7): 2033-42.

41. Lane MA, Baldwin RVI, Jesse BW. Developmental changes in ketogenic enzyme gene expression during sheep rumen development. J Anim Sci. 2002;80(6):1538-44.

42. Hertzel AV, Bernlohr DA. The mammalian fatty acid-binding protein multigene family: molecular and genetic insights into function. Trends Endocrinol Metab. 2000;11(5):175-80.

43. Wang XQ, Yang K, He YS, Lu L, Shen WF. Receptor mediated elevation in FABP4 levels by advanced glycation end products induces cholesterol and triacylglycerol accumulation in THP-1 macrophages. Lipids. 2011;46(6):479-86.

44. Harvatine KJ, Bauman DE. SREBP1 and thyroid hormone responsive spot 14 (S14) are involved in the regulation of bovine mammary lipid synthesis during diet-induced milk fat depression and treatment with CLA. J Nutr. 2006;136(10):2468-74.

45. Viturro E, Koenning M, Kroemer A, Schlamberger G, Wiedemann S, Kaske M, Meyer HHD. Cholesterol synthesis in the lactating cow: induced expression of candidate genes. J Steroid Biochem Mol Biol. 2009;115(1-2):62-7.

46. Dempsey ME. Regulation of steroid biosynthesis. Annu Rev Biochem. 1974:43:967-90.

47. Baldwin RL. Use of isolated ruminal epithelial cells in the study of rumen metabolism. J Nutr. 1998;128(2):293S-6S

48. Simons K, Toomre D. Lipid rafts and signal transduction. Nat Rev Mol Cell Biol. 2000;1(1):31-9.

49. Glavinas H, Krajcsi $P$, Cserepes J, Sarkadi B. The role of ABC transporters in drug resistance, metabolism and toxicity. Curr Drug Deliv. 2004;1 (1):27-42.

50. Sahoo S, Aurich MK, Jonsson JJ, Thiele I. Membrane transporters in a human genonne-scale metabolic knowledgebase and their implications for disease. Front Physiol. 2014:5:91.

51. Denis M, Bissonnette R, Haidar B, Krimbou L, Bouvier M, Genest J. Expression, regulation, and activity of $A B C A 1$ in human cell lines. Mol Genet Metab. 2003;78(4):265-74.

52. Jessup W, Gelissen IC, Gaus K, Kritharides L. Roles of ATP binding cassette transporters $A 1$ and $\mathrm{G} 1$, scavenger receptor $\mathrm{B}$ and membrane lipid domains in cholesterol export from macrophages. Curr Opin Lipidol. 2006; 17(3):247-57.

53. Chun YS, Shin S, Kim Y, Cho H, Park MK, Kim TW, Voronov SV, Di Paolo G, Suh BC, Chung S. Cholesterol modulates ion channels via down-regulation of phosphatidylinositol 4,5-bisphosphate. J Neurochem. 2010;112(5):1286-94.

54. Dopico AM, Bukiya AN, Singh AK. Large conductance, calcium- and voltagegated potassium (BK) channels: regulation by cholesterol. Pharmacol Ther. 2012;135(2):133-50.

55. Liao JK, Laufs U. Pleiotropic effects of statins. Annu Rev Pharmacol. 2005;45:89-118.

56. Alberts B, Johnson A, Lewis J, Raff M, Roberts K, Walter P. Molecular biology of the cell. 5th ed. New York: Garland Science; 2007.
57. Phillips T. Regulation of transcription and gene expression in eukaryotes. Nat Educ. 2008:1(1):199.

58. Penner GB, Beauchemin KA, Mutsvangwa T. An evaluation of the accuracy and precision of a stand-alone submersible continuous ruminal $\mathrm{pH}$ measurement system. J Dairy Sci. 2006;89(6):2132-40.

59. Kim D, Pertea G, Trapnell C, Pimentel H, Kelley R, Salzberg SL. TopHat2: accurate alignment of transcriptomes in the presence of insertions, deletions and gene fusions. Genome Biol. 2013;14(4):R36.

60. Robinson MD, McCarthy DJ, Smyth GK. edgeR: a bioconductor package for differential expression analysis of digital gene expression data. Bioinformatics. 2010:26(1):139-40.

61. Benjamini Y, Hochberg Y. Controlling the false discovery rate-a practical and powerful approach to multiple testing. J R Statist Soc B. 1995;57(1):289-300.

62. Mi H, Muruganujan A, Casagrande JT, Thomas PD. Large-scale gene function analysis with the PANTHER classification system. Nat Protoc. 2013;8(8):1551-66

63. Huang DW, Sherman BT, Lempicki RA. Systematic and integrative analysis of large gene lists using DAVID bioinformatics resources. Nat Protoc. 2009;4(1): 44-57.

64. Rémond D, Ortigues I, Jouany JP. Energy substrates for the rumen epithelium. Proc Nutr Soc. 1995;54(1):95-105.

65. Koboldt DC, Zhang QY, Larson DE, Shen D, McLellan MD, Lin L, Miller CA, Mardis ER, Ding L, Wilson RK. VarScan 2: somatic mutation and copy number alteration discovery in cancer by exome sequencing. Genome Res. 2012;22(3):568-76.

\section{Submit your next manuscript to BioMed Central and we will help you at every step:}

- We accept pre-submission inquiries

- Our selector tool helps you to find the most relevant journal

- We provide round the clock customer support

- Convenient online submission

- Thorough peer review

- Inclusion in PubMed and all major indexing services

- Maximum visibility for your research

Submit your manuscript at www.biomedcentral.com/submit
) Biomed Central 